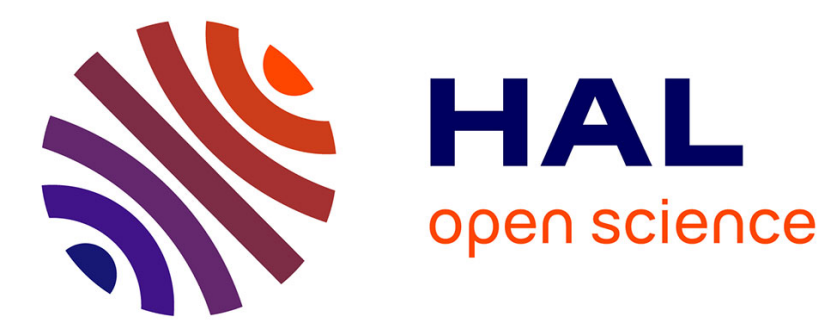

\title{
Three-dimensional numerical and analytical study of horizontal group of square anchor plates in sand
}

Hicham Mokhbi, Mekki Mellas, Abdelhak Mabrouki, Jean-Michel Pereira

\section{To cite this version:}

Hicham Mokhbi, Mekki Mellas, Abdelhak Mabrouki, Jean-Michel Pereira. Three-dimensional numerical and analytical study of horizontal group of square anchor plates in sand. Acta Geotechnica, 2018, 13 (1), pp.159-174. 10.1007/s11440-017-0557-x . hal-02882390

\section{HAL Id: hal-02882390 \\ https://hal-enpc.archives-ouvertes.fr/hal-02882390}

Submitted on 26 Jun 2020

HAL is a multi-disciplinary open access archive for the deposit and dissemination of scientific research documents, whether they are published or not. The documents may come from teaching and research institutions in France or abroad, or from public or private research centers.
L'archive ouverte pluridisciplinaire HAL, est destinée au dépôt et à la diffusion de documents scientifiques de niveau recherche, publiés ou non, émanant des établissements d'enseignement et de recherche français ou étrangers, des laboratoires publics ou privés. 
Hicham Mokhbi ${ }^{1}$, Mekki Mellas $^{1}$, Abdelhak Mabrouki $^{1}$, Jean-Michel Pereira ${ }^{2}$

1 Civil Engineering Research Laboratory, University of Biskra, BP145 Biskra 07000, Algeria

5

2 Laboratoire NAVIER, École des Ponts Paris Tech, 6 et 8 avenue Blaise Pascal, 77420 Champs-sur-Marne,

6 France

7 Abstract

8 In this paper, numerical and analytical methods are used to evaluate the ultimate 9 pullout capacity of a group of square anchor plates in row or square configurations, 10 installed horizontally in dense sand. The elasto-plastic numerical study of square 11 anchor plates is carried out using three-dimensional finite-element analysis. The soil 12 is modeled by an elasto-plastic model with a Mohr-Coulomb yield criterion. An 13 analytical method based on a simplified three-dimensional failure mechanism is 14 developed in this study. The interference effect is evaluated by group efficiency $\eta$, 15 defined as the ratio of the ultimate pullout capacity of group of $N$ anchor plates to that of a single isolated plate multiplied by number of plates. The variation of the group efficiency $\eta$ was computed with respect to change in the spacing between plates. Results of the analyses show that the spacing between the plates, the internal friction angle of soil and the installation depth are the most important parameters influencing the group efficiency. New equations are developed in this study to evaluate the group

21 efficiency of square anchor plates embedded horizontally in sand at shallow depth $(H=4 B)$. The results obtained by numerical and analytical solutions are in excellent 23 agreement.

\section{Keywords}

25 Square anchor plate, group efficiency, finite elements, pullout capacity, sand, critical 26 spacing. 


\section{Introduction}

28 Anchor plates are lightweight structural elements, buried in the ground, used to resist the pullout forces acting on geotechnical structures such as submerged pipelines, offshore structures, retaining walls, and transmission towers. They may have various shapes (circular, helical, square, rectangular or strip). They are installed in the ground horizontally, vertically or in an inclined way. In the literature there are different theoretical, numerical and experimental works investigating the behavior of an isolated anchor plate and calculate its ultimate uplift capacity. One can cite Meyerhof and Adams (1968), Das (1978), Murray and Geddes (1987), Merifield and Sloan (2006), Hanna et al (2007), Khatri and Kumar (2009, 2010, 2011), Wang et al (2013), Bhattacharya and Kumar (2014), Mabrouki and Mellas (2014), Ardebili et al (2016), among others.

However, little information is available in the literature concerning the ultimate pullout capacity of a group of anchor plates. Table 1 presents some experimental, analytical and numerical works. Meyerhof and Adams (1968) proposed a theoretical relationship for calculating the ultimate pullout force of group of circular or rectangular foundations, buried in sand or in clay. Das and Yang (1987) have developed a physical model to evaluate the ultimate pullout force of a group of circular anchor plates buried in medium dense sand. They compared their results in terms of group efficiency with the theoretical solution of Meyerhof and Adams (1968), and they found that the ratio spacing/diameter $(S / D)$ for a group efficiency $\eta=100 \%$, for a given configuration, is approximately equal to the double of the one obtained theoretically.

49 However, the general trend of the evolution of the group efficiency with respect to $S / D$ ratio is similar to that of the theory.

51 In the present study, special attention was paid to the experimental model of Geddes 
53

54

55

56

57

58

59

60

61

62

63

64

65

66

67

68

69

70

71

72

73

embedded in a dense sand at a fixed depth, in different configurations. They reported that, from a critical spacing ratio $\left(S_{c r} / B=2.9\right.$ for the test conditions used), the maximum group efficiency is $100 \%$ and remains at that level when increasing the spacing. This critical spacing is valid for all configurations and for a number of studied anchor plates.

Abbad et al. (2013), have carried out an experimental study of the interaction of the failure zones of square anchor plates installed at a depth of $5 B$ in an analogical environment formed by plastic granules. They used digital photographs at high resolution processed by image correlation software to observe the displacement field and plane strain of the analogical environment. They have reported that a minimum spacing between axes of about seven times the width of the plate $(7 B)$ is necessary for two neighboring anchor plates to act independently of each other.

In addition, other analytical studies of interferences within a group of strip anchor plates, were established by Kumar and Kouzer (2008a), Kouzer and Kumar (2009a, 2009b), Merifield and Smith (2010), Ghosh and Kumari (2012), Kumar and Naskar (2012), and Sahoo and Kumar (2014a, 2014b). These works fall within the limit analysis framework, using the lower bound or the upper bound method. Table 1 shows the previous experimental and analytical works related to the study of the interference of anchor plates in soils.

The main objective of this study is, on the one hand, to investigate numerically, using three-dimensional non-linear finite element analysis, the group efficiency of square anchor plates buried horizontally in a dense sand for several values of spacing/width ratio $(S / B)$. The effect of parameters like installation depth, internal friction angle of soil, anchor roughness, and flow rule have been investigated numerically. On the other hand, an additional objective is to develop an analytical solution of the group efficiency of square anchor plates buried horizontally in the sand based on a failure 
79

80

81

82

83

84

85

86

87

88

89

90

91

92

93

94

95

96

97

98

99

100

101

102

103

mechanism available in the literature, where a modification of the shape of the failure mechanism was introduced to simplify the calculation of the interference of failure mechanisms.

This study aims at highlighting recommendations concerning the calculation of pullout capacity of group of square anchor plates buried horizontally in a dense sand.

\section{Numerical modeling}

In this study, a three-dimensional numerical model was developed using the finite element method in Plaxis software, to investigate the ultimate uplift capacity of a group of square plate anchors. From previous experimental and theoretical studies on groups of plate anchors in soil (Table 1), the experimental work of Geddes and Murray (1996) seems the most appropriate as a reference for our work because it concerns the problem of square plates and contains the required data for numerical modeling. Geddes and Murray (1996) have performed a series of laboratory pullout tests on group of square plate anchors buried horizontally in dense sand. These tests were conducted in a steel box of size $1.28 m \times 1.22 m \times 0.89 m$. The plate anchor have a square shape of width $B=50.8 \mathrm{~mm}$, buried at a fixed depth $H=203.2 \mathrm{~mm}$ to give a ratio $H / B=4$. Vertical uplift tests were carried out on two and five square plates in row configuration with constant spacing; and on groups of four square plates placed in a square configuration.

The symmetry of the problem enables to take a quarter model in all calculations as shown in Fig.1 which presents an example of a group of four anchor plates in square configuration. The dimensions of the numerical model adopted in all calculations (width, length and height) are constants according to the experimental model of Geddes and Murray (1996). The width of the model adopted is $0.61 \mathrm{~m}$ and the height is $1 \mathrm{~m}$; the square plate anchor have a width of $B=50 \mathrm{~mm}$. It is verified that these 
104 dimensions do not prevent the development of the failure mechanism for the large

105 values of the spacing $(S)$ considered in this study.

106 The small displacement assumption has been considered in all numerical analysis.

107 The adopted soil model is a linear elastic-perfectly plastic model, obeying Mohr-

108 Coulomb criterion with a non-associative flow rule. Referring to the study of Bolton

109 (1986) on the strength and dilatancy of sands, the adopted dilation angle is $\psi^{\prime}=\varphi^{\prime}-$

$11030^{\circ}$. The anchor plate is modeled by plate elements with a linear elastic model. The

111 values of soil parameters and elastic stiffness parameters of plate anchor used in this

112 investigation are shown in Table 2. The soil parameters were taken from the Geddes

113 and Murray (1996) study, and the elastic parameters of the material constituting the

114 anchor plates were estimated from the literature studies (e.g., Hanna et al, 2011,

115 Aghazadeh Ardebili et al, 2015, Ghosh, and Kumari, 2012).

116 Interface elements are used between soil and anchor plate elements to ensure sol-

117 plate interaction. This type of interface elements allow for soil detachment. The 118 interface behavior is defined by Mohr Coulomb criterion, with shear-strength 119 characteristics calculated by the introduction of the strength reduction factor $R_{\text {inter }} \leq$ 1201 , which gives the values of strength parameters of the interface element from the 121 soil parameters by applying the strength reduction method suggested by Plaxis 122 (Brinkgreve and Vermeer 2001) as follows:

$123 c_{i}^{\prime}=R_{\text {inter }} c_{\text {soil }}^{\prime}$

$124 \tan \varphi_{i}^{\prime}=R_{\text {inter }} \tan \varphi_{\text {soil }}^{\prime} \leq \tan \varphi_{\text {soil }}^{\prime}$

$125 \psi_{i}^{\prime}=0^{\circ}$ for $R_{\text {inter }}<1$, otherwise $\psi_{i}^{\prime}=\psi_{\text {soil }}^{\prime}$

126 where $c_{i}^{\prime}, \varphi_{i}^{\prime}$ and $\psi_{i}^{\prime}$ are the cohesion, the friction angle and the dilation angle of 127 interface elements respectively. 
128 A modified shear box test carried out by Geddes and Murray (1996) gave an

129 interface friction angle of $10.6^{\circ}$ for the sand studied in contact with polished steel 130 plates, of the same kind as the anchors plates used in the uplift test. So for our case

131 the strength reduction factor $R_{\text {inter }}=0.19$.

132 Prescribed upwards displacements were applied at the nodes of anchor plates, and 133 increase gradually until the stabilization of the resultant force which corresponds to 134 the ultimate pullout force $Q_{u}$ of the anchor plates group (Fig. 5). It should be noted 135 that, using a displacement loading procedure, the parameters of the plate anchor do 136 not affect the calculation results.

137 Before adopting the reference numerical model, several calculation tests were 138 executed to check the influence of the mesh and the size of the model on calculation 139 results, which allowed to suggest not only the use of a fine mesh in the vicinity of the 140 anchor plate but also that the plate element itself must imperatively be discretized in 14110 elements minimum on the $x-y$ plane to get more accurate results. It was also 142 verified that the boundaries of the numerical model based on the dimensions of the 143 experimental model of Geddes and Murray (1996) have no effect on the value of the 144 ultimate force obtained. It was finally checked that the values of the elastic 145 parameters of soil have a negligible effect on the ultimate force computed by the 146 numerical analysis.

\section{Numerical results}

148 The numerical finite element analyses that have been performed in this study 149 concern the calculation of the ultimate pullout capacity of a group of square anchor 150 plates, installed in row configuration: two $(2 \times 1)$, three $(3 \times 1)$, four $(4 \times 1)$ and five $(5$ $151 \times 1)$ square plates, or in square configuration: four $(2 \times 2)$ and nine $(3 \times 3)$ square 152 plates, with a constant spacing $S$ between the plates varying between 0 and $2.5 B$. 
153 The group efficiency $\eta$ was analyzed as a function of the spacing/width ratio $(S / B)$ for

154 both row and square configurations for these relatively low values of $S / B$ ratio. Then

155 the critical spacing $S_{c r}$ between anchor plates was evaluated (corresponding to $\eta=$ $156100 \%)$. $S_{c r}$ was defined as the distance from which each anchor plate acts 157 independently without interference between failure mechanisms (results discussed in 158 section 6).

\section{3. 1 Group of square anchor plates in row configuration}

160 Before starting the numerical analyses for group of plates, the pullout capacity of an 161 isolated square anchor plate was calculated. The evolution of pullout load with 162 displacement was plotted in Fig. 5 (bottom curve). The failure mechanism of this 163 isolated square anchor plate can be observed in Fig. 2. Its shape can be considered 164 as a truncated cone with slightly curved failure planes near the ground surface.

165 In order to investigate the influence of elastic parameters of soil on the ultimate 166 pullout capacity, the case of a single square anchor plate are analysed with different 167 values of Young's modulus ( $E=10,30$ and $60 \mathrm{MPa}$ ). Fig. 3 shows the results 168 obtained for $H / B=4$ and $H / B=6$; It can be observed that the values of the elastic 169 parameters have a small effect on the ultimate pullout capacity. However, for great 170 values of $E$ the ultimate load is reached for a smaller displacement.

171 Fig. 4 illustrates a group of square anchor plates of width $B$, installed in row 172 configuration with a similar spacing $S$. The total line length is noted $L$.

173 Fig. 5 shows the results of the ultimate pullout load as a function of displacement for 174 a group of two square anchor plates with different values of $S / B$ ratio varying from 0 175 to 2 , indicating that the force $Q_{u}$ increases with increasing spacing between the two 176 anchor plates. This trend illustrates the presence of group effects on the ultimate 177 pullout capacity. Fig. 6 presents the total displacements obtained in the case of two 
178 anchor plates with a ratio of $S / B=2$. It also shows the interference of the failure

179 mechanisms of the two adjacent plates.

180 The group efficiency $\eta$ was calculated by the following conventional relation (Das 181 (1990), Geddes and Murray (1996), Emirler et al (2015)):

$$
\eta(\%)=\frac{\text { Ultimate load of group of } N \text { anchors } \times 100}{N \times \text { ultimate load of an isolated anchor }}
$$

182 with $N$ the total number of anchor plates.

183 Fig. 7 shows the evolution of the group efficiency of square anchor plates in row 184 configuration (two $(2 \times 1)$, three $(3 \times 1)$, four $(4 \times 1)$ and five $(5 \times 1))$ with the 185 spacing/width ratio $(S / B)$. In the same figure are plotted the experimental results 186 obtained by Geddes and Murray (1996) in the case of two $(2 \times 1)$ and five $(5 \times 1)$ 187 plates.

188 The numerical results show that the evolution of the group efficiency as a function of $189(S / B)$ ratio is perfectly linear, and may be fitted with Equations (2), (3), (4) and (5) for 190 configurations $(2 \times 1),(3 \times 1),(4 \times 1)$ and $(5 \times 1)$ respectively. For the case of two plates 191 ( $2 \times 1)$, the group efficiency $\eta$ increases linearly from $61 \%$ for $S / B=0$ corresponding 192 to a rectangular plate $L / B=2$ to $78 \%$ for $S / B=2$. For the case of three plates $(3 \times 1)$, $193 \eta$ increase linearly from $48 \%$ for $S / B=0$ corresponding to a rectangular plate $L / B=3$ 194 to $77 \%$ for $S / B=2.5$. For the case of four plates $(4 \times 1), \eta$ increase linearly from $41 \%$ 195 for $S / B=0$ corresponding to a rectangular plate $L / B=4$ to $74 \%$ for $S / B=2.5$. For five 196 plates $(5 \times 1), \eta$ increase also linearly from $37 \%$ for $S / B=0$ corresponding to a 197 rectangular plate $L / B=5$ to $72 \%$ for $S / B=2.5$.

$$
\begin{aligned}
& \eta_{2 \times 1}(\%)=8.537 \frac{S}{B}+60.96 \\
& \eta_{3 \times 1}(\%)=11.45 \frac{S}{B}+48.13
\end{aligned}
$$




$$
\begin{aligned}
& \eta_{4 \times 1}(\%)=13.25 \frac{S}{B}+40.68 \\
& \eta_{5 \times 1}(\%)=13.85 \frac{S}{B}+36.94
\end{aligned}
$$

198 The values of group efficiency obtained experimentally by Geddes and Murray (1996) 199 are larger than the numerical results, except for the first point $(S / B=0)$ which is 200 superimposed to the numerical point in both cases $(2 \times 1)$ and $(5 \times 1)$. For the case of 201 five plates $(5 \times 1)$, the difference between the experimental and numerical results 202 increases with the increase of $S / B$ ratio, and remains nearly constant around $10 \%$ for 203 the case of two plates $(2 \times 1)$. However, the experimental results also show a linear 204 trend from the second point corresponding to $S / B=0.25$ or $S / B=0.5$. On this point, 205 Geddes and Murray (1996) reported that the relationship between $S / B$ and the group 206 efficiency demonstrates an initial perturbation followed by a linear trend.

207 The group efficiency obtained experimentally varies from about $59 \%$ for $S / B=0$ to 208 about $90 \%$ for $S / B=2$ in the case of two plates $(2 \times 1)$. For five plates, $\eta$ varies from 209 about $37 \%$ for $S / B=0$ to about $71 \%$ for $S / B=2.5$.

210 From these results in row configuration, we can conclude that the group efficiency of $211 N$ plates is lower than that of $(N-1)$ plates for the same spacing $S$, and this 212 difference of efficiency decreases when the spacing/width ratio $(S / B)$ increases.

\section{3. 2 Group efficiency of square plates in square configuration}

214 For a square configuration, Fig. 8 illustrates the two cases studied: groups of four (2

$215 \times 2)$ and nine $(3 \times 3)$ square anchor plates. Fig. 9 presents the total displacements 216 obtained in the case of nine anchor plates with a ratio of $S / B=2$. It also shows the 217 interference between failure mechanisms of plates.

218 Fig. 10 shows the numerical results of these cases in comparison with the experimental results obtained by Geddes and Murray (1996). The numerical results 
220 show that $\eta$ increases linearly as a function of S/B ratio, following the two Equations

221 (6) and (7) for the case of four $(2 \times 2)$ and nine $(3 \times 3)$ plates respectively. For the 222 case of four plates $(2 \times 2), \eta$ evolves linearly from $34 \%$ for $S=0$ (corresponding to a 223 single square plate of width equal to $2 B$ ), to $67 \%$ for $S / B=2.5$. For the case of nine $224(3 \times 3)$ plates, $\eta$ increase from $20 \%$ for $S=0$ (corresponding to the case of a single 225 square plate of width equal to $3 B$ ), to $52 \%$ for $S / B=2.5$.

226 The experimental results of Geddes and Murray (1996) for four square plates (2 x 2), 227 shows that $\eta$ evolves almost linearly with $S / B$ ratio, from $34 \%$ for $S=0$ to 228 approximately $85 \%$ for $S / B=2.5$. However, the experimental values of $\eta$ are larger 229 than the numerical values except for the case of $S / B=0$ where the values of $\eta$ are 230 equal, then the difference between the numerical and experimental values of $\eta$ 231 increases gradually with the increase of $S / B$.

$$
\begin{aligned}
& \eta_{2 \times 2}(\%)=13.39 \frac{S}{B}+33.48 \\
& \eta_{3 \times 3}(\%)=12.92 \frac{S}{B}+19.81
\end{aligned}
$$

232 It is also remarkable that for any given value for $S / B$ ratio, the group efficiency of four 233 square anchor plates installed in square configuration is lower than in the case of 234 four square anchor plates installed in row configuration. The reason is that in square 235 configuration, the failure mechanism of each of the four plates interferes with that of 236 the two or three other plates. In row configuration, the failure mechanism of each of 237 the intermediate plates interferes with that of the two nearby plates, and the failure 238 mechanism of each of the edge plates interferes only with that of a single plate. This 239 difference of group efficiency between a row and square configuration becomes 240 larger with the increase of the number of anchor plates. 


\section{3 Load factors}

242 The previous numerical results highlighted that the group efficiency of a group of 243 square anchor plates installed horizontally in sand, in row or square configuration, 244 evolves linearly with $S / B$ ratio. In order to establish a general equation of the group 245 efficiency of $N$ anchor plates, the previous data of group efficiency, for row and 246 square configurations, were redrawn in terms of load factor $F_{L}$ versus $L / B$ ratio. 247 According to Geddes and Murray (1996), the following relationship holds:

$$
\frac{L}{B}=n+(n-1) \frac{S}{B}
$$

248 with $\mathrm{n}$ the number of plate per row,

$$
F_{L}=\frac{\text { Ultimate load of } N \text { plates }}{\text { Ultimate load of a single isolated plate }}
$$

249 or

$$
F_{L}=\eta \times N / 100
$$

250 Fig. 11 presents the variation of the load factor according to $L / B$ ratio for all row 251 configurations studied previously. The load factor evolves linearly with $L / B$ ratio for 252 two, three, four and five anchor plates in row configuration. This linear relation is best 253 fitted by the following equation:

$$
F_{L}=0.182(L / B)+0.866
$$

254 From Equations (8), (10) and (11), we can write a general relation (12) of the group 255 efficiency of $n$ square anchor plates installed horizontally in the sand in row 256 configuration $(n=N)$. Nevertheless, this relation is valid only for the geotechnical and 257 geometrical characteristics chosen in this study. 


$$
\eta_{n \times 1}(\%)=\frac{18.2}{n}\left(n+(n-1) \frac{S}{B}\right)+\frac{86.6}{n}
$$

258 Besides, by drawing the curve of the load factor according to $L / B$ ratio for the case of

259 four and nine anchor plates in square configuration (Fig. 12), a global linear relation

260 of the evolution of the load factor is obtained:

$$
F_{L}=0.561(L / B)+0.167
$$

261 So, from equations (8), (10), and (13) we can write the general relation (14) of the 262 group efficiency of $(N=n \times n)$ square anchor plates installed horizontally in the sand 263 in square configuration, which also is valid only for the geotechnical and geometrical 264 characteristics considered in this study:

$$
\eta_{n \times n}(\%)=\frac{56.1}{n^{2}}\left(n+(n-1) \frac{S}{B}\right)+\frac{16.7}{n^{2}}
$$

265

266

267

268

269

270

\section{Parametric study}

The previous numerical calculations have established the general Equations (12) and (14) of the group efficiency for row and square configurations respectively. These relations concern the case of $H / B=4$, and involve the following variables: number of anchor plates, spacing between anchor plates and width of plates. However, a parametric study is needed to verify the influence of various parameters on the

271 obtained results. To this aim, a numerical parametric study was carried out on a 272 group of two square anchor plates, studying the influence of installation depth, 273 internal friction angle of soil, flow rule and roughness of anchors.

\section{$274 \quad 4.1$ Influence of installation depth}

275 To study the influence of installation depth on the group efficiency, the ultimate 276 pullout capacity of two square anchor plates was calculated for a depth/width ratio 
$277 H / B=2$ and $H / B=6$. Then the group efficiency was calculated and compared with

278 those obtained for the reference model $(H / B=4)$ as shown in Fig. 13.

279 Fig. 13 shows that the group efficiency for a given spacing decreases when the $H / B$ 280 ratio increases. Indeed, the critical spacing $\left(S_{c r}\right)$ increases with depth $(H)$. This is 281 explained by the relationship between the critical spacing and the installation depth 282 theoretically estimated by $S_{c r}=2 H \tan \theta$, with $\theta$ is the inclination angle of the failure 283 plane with the vertical as shown in Fig. 21.

284 In previous studies, the installation depth has also an influence on the shape of 285 failure mechanisms. There is a critical embedment ratio which presents the transition 286 between shallow anchor behaviour and deep anchor behaviour. Meyerhof (1973) 287 proposed a critical embedment ratio $H / B=4$ for square anchors in loose sand, and it 288 increases up to about 8 in dense sand. Also, Das (1983) proposed an empirical 289 correlation for the critical embedment ratio for square anchor plates in the form $\mathrm{H} / \mathrm{B}=5.5+0.166(\varphi-30),\left(\right.$ for $\left.30^{\circ} \leq \varphi \leq 45^{\circ}\right)$.

291 Fig. 14 shows the total displacement for the case of two square anchor plates 292 embedded at different depths with $H / B$ varying from 4 to 10 . The mechanisms are 293 depicted by the contours of finite element displacement; where the same scale was 294 used to present the displacement field for all embedment ratio values. It is seen that 295 from embedment ratio $H / B \geq 8 H$ the failure mechanism begins to develop locally. 296 From the present study, the embedment ratio $H / B=8$ can be considered as the 297 critical embedment ratio.

\section{$298 \quad 4.2$ Influence of internal friction angle}

299 The reference numerical model was studied with an internal friction angle $\varphi^{\prime}=43.6^{\circ}$.

300 However, to study the influence of this parameter on the group efficiency, other 301 numerical calculations were performed, also for a group of two square anchor plates, 
302 with other values of the internal angle friction $\varphi^{\prime}=30^{\circ}$ and $\varphi^{\prime}=20^{\circ}$. For these values

303 of $\varphi^{\prime}$, the adopted dilation angle is equal to zero. The results of numerical calculations

304 are presented in Fig. 15 showing a little influence compared to the depth parameter

305 on the group efficiency. $\eta$ increases by $8 \%$ when $\varphi^{\prime}$ decreases from $43.6^{\circ}$ to $20^{\circ}$. This

306 influence can be explained by the relation of the failure mechanism with the internal

307 friction angle. Some authors such as Clemence and Veesaert (1977) found that the

308 inclination angle of the failure plane with the vertical is equal to the half of the internal

309 friction angle of soil. Murray and Geddes (1987), and Merifield et al (2006) found that

310 this inclination angle is equal to the internal friction angle. So, when $\varphi^{\prime}$ decreases the

311 interference between failure mechanisms decreases and $\eta$ increases.

\subsection{Influence of dilation angle}

313 To study the influence of the flow rule on the group efficiency, other numerical 314 calculations were established for the case of two square anchor plates. An 315 associated flow rule $\left(\psi^{\prime}=\varphi^{\prime}\right)$ was considered, and the obtained results of the group 316 efficiency were compared with the results of the reference case calculated with a 317 non-associated flow rule $\left(\psi^{\prime}=\varphi^{\prime}-30^{\circ}\right)$. This comparison is presented in Fig. 16 and 318 shows an almost negligible effect on the group efficiency according to $S / B$ ratio. 319 However, it should be noted that there is a significant influence of the dilation angle 320 on the value of the ultimate pullout capacity, which is overestimated with an 321 associated flow rule (up to $38 \%$ ).

\section{$322 \quad 4.4$ Influence of anchor roughness}

323 In the reference model, the interface between the soil and the anchor plate was 324 determined by using a strength reduction factor $R_{\text {inter }}=0.19$. To study the influence 325 of anchor roughness on the group efficiency, other calculations were performed for a 326 group of two square anchor plates, with the following values of the strength reduction 
327 factor $R_{\text {inter }}=0.33 ; 0.5 ; 0.75$ and 1 . The results of group efficiency are presented in

328 Fig. 17, which show that there is a very little influence on the values of group 329 efficiency. This is can be explained by the shape of failure mechanism, where there is 330 no significant mobilization of shearing resistance between the soil and the anchor 331 plate during the pullout action. Rowe and Davis (1982b) found that the roughness 332 has a negligible effect on the capacity of horizontal anchors at all depths, but 333 significantly increases that of shallow vertical anchors $(H / B<3)$. For this latter case, 334 they found that the effect of roughness is increased further if the soil is dilatant.

\section{Analytical solution for $n$ square anchor plates in row configuration}

\subsection{Isolated anchor plate}

Murray and Geddes (1987) have developed a failure mechanism using the upper bound limit analysis, for a rectangular anchor plate installed horizontally in a frictional soil, and subjected to a vertical pullout loading. This failure mechanism consists in a 340 failure plane inclined at an angle $\varphi^{\prime}$ to the vertical at the edge of the plate. At the 341 corners the failure mechanism consists in a portion of a circular cone. They have obtained the following expression for the break-out factor $N_{\gamma}$ :

$$
N_{\gamma}=1+\frac{H}{B} \tan \varphi^{\prime}\left(1+\frac{B}{L}+\frac{\pi}{3} \frac{H}{L} \tan \varphi^{\prime}\right)
$$

343 To simplify the analytical calculation of the interference of a group of square anchor 344 plates, the portion of a circular cone at the corners were replaced by a vertical 345 pyramid. The inclination angle $(\theta)$ of the failure plane with the vertical was adopted 346 using this empirical relation $\theta=0.785 \varphi^{\prime 1.1}$ with $\varphi^{\prime}$ is expressed in degree (Fig. 18).

347 Following the theory of Mors (1959), the ultimate pullout capacity is assumed equal to 348 the weight of soil located within the failure mechanism; and the frictional resistance 349 acting along the failure surface was ignored. Ilamparuthi et al. (2002) have reported 
350 that the method of Mors (1959) is usually conservative for shallow anchors but

351 overpredicts pullout capacity for deeper anchors. This method was also followed by 352 Ganesh and Sahoo (2015) to estimate the ultimate uplift resistance of circular anchor 353 plate. They reported that the frictional resistance acting along the failure surface can 354 be ignored, conservatively, for the case of shallow anchors. It is worthwhile noting 355 that the present study considers the anchor plates embedded at shallow depth $356(H=4 B)$.

357 The break-out factor of this modified failure mechanism is given in equation (16) (see 358 details in appendix A). The values of $N_{\gamma}$ obtained by this expression (16) give a very 359 satisfactory agreement with the upper bound results obtained by Murray and Geddes 360 (1987), and the lower bound results obtained by Merifield et al. (2006) as shown in 361 Fig. 19.

$$
N_{\gamma \text { isolated }}=1+2 \frac{H}{B} \tan \theta+\frac{2}{3}\left(\frac{H}{B}\right)^{2} \tan ^{2} \theta
$$

362 In order to examine the effect of soil strength along the failure surface on the ultimate 363 pullout capacity, numerical analyses were carried out by modeling a full-scale square 364 plate $(B=1 \mathrm{~m})$ with embedment ratio $H / B$ varying from 1 to 5 , and $\phi^{\prime}=20^{\circ}, 30^{\circ}$ and $36540^{\circ}$ by considering an associative flow rule. The model adopted in these numerical 366 analyses, has a depth of $10 \mathrm{~m}$ and extends $6 \mathrm{~m}$ beyond the planes of symmetry.

367 The values of the break-out factor $\mathrm{Ny}$ obtained from the present numerical analyses 368 were compared with those calculated with the expression (16) as shown in Fig. 20. 369 The comparison shows that the values of $\mathrm{Ny}$ obtained by the expression (16) are 370 slightly smaller than the numerical values. Consequently, when the soil strength 371 along the failure surface is ignored, the result always errs on the safe side; it 372 underestimates the ultimate pullout capacity. However, the relative error from the use 
373 of this assumption varies between $3 \%$ and $17 \%$, and it increases slightly with the

374 increase in embedment ratio.

\section{$375 \quad 5.2$ Two square anchor plates}

376 For a group of two square anchor plates spaced by $S<2 H \tan \theta$, the ultimate pullout capacity of each anchor plate is simply equal to the weight of the soil located within

378 the failure mechanism (defined by points $a, b, c, d$, e for the left anchor, as shown in 379 Fig. 21). The break-out factor corresponding to this volume is noted by $N_{\text {yend }}$ and 380 given by: (see details in appendix $B$ )

$N_{\gamma \text { end }}=1+\frac{1}{3}\left(\frac{H}{B}\right)^{2}(\tan \theta)^{2}+\frac{1}{2}\left(3+\frac{S}{B}\right) \frac{H}{B} \tan \theta+\frac{1}{8} \frac{S}{H} \frac{S}{B}\left(\frac{1}{3} \frac{S}{B}-1\right) \cot \theta-\frac{1}{4}\left(\frac{S}{B}\right)^{2}+\frac{1}{2} \frac{S}{B}$

381 The group efficiency of two anchor plates noted $\eta_{2 \times 1}$ can be calculated with the 382 following relationship:

$$
\eta_{2 \times 1}(\%)=\frac{N_{\gamma \text { end }}}{N_{\gamma \text { isolated }}} \times 100
$$

383 Fig. 22 shows the group efficiency of two anchor plates as a function of $S / B$ ratio, as 384 predict by Equation (18), in comparison with our numerical results and the 385 experimental results obtained by Geddes and Murray (1996). Additional calculations were performed using Plaxis software for $(S / B=4.5,5$ and 5.5).

In general, it can be noted that the analytical results are in good agreement with numerical results. However, the experimental results obtained by Geddes and Murray (1996) show higher values than both analytical and numerical results.

\section{3 n square anchor plates in row configuration}

391 For a group of $n$ square anchor plates spaced by $S<2 H \tan \theta$, the ultimate pullout 392 capacity of an intermediate anchor plate is simply equal to the weight of the soil 393 located within the failure mechanism defined by points a, b, c, d, e, f as shown in Fig. 
23. The break-out factor corresponding to this volume is noted $N_{\gamma \text { inter }}$ and given by:

395 (see details in appendix C)

$$
N_{\gamma \text { inter }}=1+\left(1+\frac{S}{B}\right) \frac{H}{B} \tan \theta-\frac{1}{3} \frac{\mathrm{S}}{\mathrm{B}} \frac{\mathrm{S}}{\mathrm{H}}\left(\frac{1}{4} \frac{\mathrm{S}}{\mathrm{B}}-1\right) \cot \theta-\frac{1}{2}\left(\frac{S}{B}\right)^{2}+\frac{S}{B}
$$

396 In this case, the group efficiency of $n$ anchor plates can be calculated with the 397 following expression:

$$
\eta_{n \times 1}(\%)=\frac{(n-2) N_{\gamma \text { inter }}+2 N_{\gamma \text { end }}}{n N_{\gamma \text { isolated }}} \times 100
$$

398 Fig. 24 shows the comparison of numerical, analytical and experimental results of the 399 group efficiency of five square anchor plates in row configuration. These results 400 correspond to small values of the spacing between the plates $(0<S / B<2)$. A good 401 agreement is observed between the analytical results and the numerical results.

4026 Critical spacing for two square anchor plates

403 Based on previous analytical and numerical results, we can determine the critical 404 spacing for which two anchor plates (placed at a depth $H=4 B$ in this study) act 405 independently, so that the group efficiency is equal to $100 \%$.

406 The numerical results highlight that a critical spacing of $S_{c r}=5.5 B$, is necessary for a 407 group of anchor plates installed in linear configuration to obtain a group efficiency of $408100 \%$. The critical spacing obtained by equation (12) is $S_{c r}=4.24 B$. However, the 409 additional calculations performed for verification by Plaxis software have given a 410 group efficiency $\eta=97 \%$ for $S / B=4.24$ as shown in Fig. 22 .

411 The analytical calculation have given results very similar to the numerical results 412 especially for small values of $S / B(0<S / B<2)$. However the critical spacing obtained 413 analytically for $\eta=100 \%$ is $S_{c r}=7.5 B$ as shown in Fig. 22 . Despite this remarkable 414 difference between the critical spacing obtained by the numerical calculation and that 415 obtained by an analytical solution, the relative error between them is of the order of 
$4163.86 \%$ for a critical spacing $S_{c r}=5.5 B$. On the other hand, Geddes and Murray

417 (1996) found in their experimental study a critical spacing of $S_{c r}=2.9 B$.

418 In addition, there is little information in the literature on the critical spacing with the 419 exception of the works presented in Table 3. It is important to examine the 420 experimental study of Abbad et al. (2013) on the interference of square anchor plates 421 ( $B=5 \mathrm{~cm})$ installed at a depth of $H=5 B$ in a material made of plastic grains with a 422 diameter of $1 \mathrm{~mm}$. The analogical medium has a relative density of $\mathrm{Dr}=96 \%\left(e_{\min }=\right.$ $\left.4230.302, e_{\max }=0.855\right)$, with a dry unit weight of $\gamma_{d}=14,6 \mathrm{kN} / \mathrm{m}^{3}$, a null cohesion and an 424 initial friction angle $\varphi=39^{\circ}$. Using high resolution digital pictures, they have found 425 that a minimum spacing $S_{c r}=6 B$, is necessary for two anchor plates to act 426 independently.

427 Das and Yang (1987) has developed an experimental study for circular anchor plates 428 embedded in a sand with $\varphi^{\prime}=37^{\circ}$, he found a critical spacing $S_{c r}=3 D$. For the same 429 characteristics, Meyerhof and Adams (1986) found $S_{c r}=1.8 D$.

430 The difference observed between the critical spacing obtained numerically and that 431 obtained analytically is attributed to the shape of the failure mechanism. Analytical 432 calculations consider an associated soil $\left(\psi^{\prime}=\varphi^{\prime}\right)$, which overestimates the ultimate 433 pullout capacity and provides a larger failure mechanism, thus requiring a bigger 434 critical spacing. Inversely, the numerical calculations, account for a non-associated 435 flow rule $\left(\psi^{\prime}=\varphi^{\prime}-30^{\circ}\right)$ which induce a narrower failure mechanism thus requiring a 436 smaller critical spacing.

\section{Conclusion}

438 The ultimate pullout capacity of a group of square anchor plates in row or square 439 configurations was calculated, using three-dimensional finite elements analyses. The 440 square anchor plates were installed horizontally in dense sand and pulled vertically. 441 The soil is characterized by the Mohr-Coulomb yield criterion and non-associative 
442 flow rule. In this study, a simple three-dimensional failure mechanism has been

443 proposed to evaluate the anchor break-out factor and the group efficiency. The

444 evolution of the group efficiency $\eta$ with the spacing/width ratio $(S / B)$ was analyzed

445 and compared with results available in the literature.

446 In this paper, a numerical parametric study was conducted on a group of two square 447 anchor plates to identify the most influential parameters on the group efficiency. This 448 parametric study revealed that the group efficiency $\eta$ increases considerably with the 449 decrease of the internal friction angle $\varphi^{\prime}$, and the installation depth $H$. On the other 450 hand, $\eta$ is slightly influenced by the anchor roughness and the choice of an 451 associative flow rule. Nevertheless, it is worthwhile noting that the associative flow 452 rule highly overestimates the value of the ultimate pullout capacity. The group 453 efficiency of $N$ square anchor plates installed in row configuration is greater than that 454 of $N$ square anchor plates installed in square configuration.

455 The comparison of the numerical results with analytical solutions confirmed that the 456 proposed failure mechanism predict a group efficiency values in good agreement with 457 those obtained by elasto-plastic analyses. New equations are developed in this study 458 to evaluate the group efficiency of shallow square anchor plates $(H=4 B)$. The group 459 efficiency evolves linearly with $S / B$ ratio, until a critical value of the spacing between 460 plates beyond which the anchor plates act independently. For this critical spacing, the 461 ultimate pullout load of the group arrives at its maximal value and remains stable, in 462 spite of the increase of the spacing. The value of critical spacing for which the two 463 square anchor plates can be assumed isolated, as predicted by the present 464 numerical computations, is approximately 5.5 times the width of the plate $B$. 


\section{References}

1. Abbad, H., Meghachou, M., Dekar, C., and Daoud, S. M. (2013). Interaction of Rupture Zones of Adjacent Anchor Plates in an Analogical Medium. ETASR Engineering, Technology \& Applied Science Research, 3(6):562-565.

2. Ardebili ZA, Gabr MA, Rahman MS (2016). Uplift Capacity of Plate Anchors in Saturated Clays: Analyses with Different Constitutive Models. International Journal of Geomechanics, 16(2), 4015053.

3. Bhattacharya, P., and Kumar, J. (2014). Vertical pullout capacity of horizontal anchor plates in the presence of seismic and seepage forces. Geomechanics and Geoengineering, 9(4):294-302.

4. Bolton, M. D. (1986). The strength and dilatancy of sands. Géotechnique 36(1):65-78

5. Brinkgreve, R.B.J., and Vermeer, P.A. (2001). Plaxis Finite Element Code for Soil and Rock Analyses, Version 1, BALKEMA.

6. Clemence SP, Veesaert CJ (1977) Dynamic pullout resistance of anchors in sand. In: roceedings of the International Symposium on Soil-Structure Interaction, Roorkee, India, pp 389-397

7. Das B. M., Yang Jin-Kaun (1987), Uplift Capacity of Model Group Anchors in Sand. Foundations for Transmission Line Towers, Geotechnical Special Publication No. 8, ASCE

8. Das, B. M. (1978). Model tests for uplift capacity of foundations in clay. Soils and Found. 18(2):17-24.

9. Das, B.M., (1983). A procedure for estimation of uplift capacity of rough piles. Soils and Found., Japan, 23(3):122-126.

10. Das, B. M. (1990). Earth Anchors. Developments in Geotechnical Engineering, 50: 1-241. 
11. Emirler, B. Bildik, S., and Laman, M. (2015). Numerical Investigation of Group Anchors. IFCEE 2015 @ ASCE 279-288.

12.Ganesh, R., and Sahoo, J. P. (2015). Influence of ground water on the ultimate uplift resistance of circular plate anchors. $50^{\text {th }}$ Indian geotechnical Conference $17^{\text {th }}-19^{\text {th }}$ December 2015, Pune, Maharashtra, India.

13. Geddes, J.D., and Murray, E.J. (1996). Plate anchor groups pulled vertically in sand. J. Geotech. Engrg., ASCE 122(7):509-516.

500

501

14. Ghosh, P., and Kumari, R. (2012) Seismic interference of two nearby horizontal strip anchors in layered soil. Nat Hazards, 63:789-804

502

503

504

505

506

507

508

509 15. Hanna, A., Ayadat, T., and Sabry, M. (2007). Pullout resistance of single vertical shallow helical and plate anchors in sand. Geotechnical and Geological Engineering, 25(5):559-573.

16. Hanna A, Rahman F, Ayadat T (2011) Passive earth pressure on embedded vertical plate anchors in sand. Acta Geotechnica, 6(1), 21-29.

17. llamparuthi, K., Dickin, E. A., and Muthukrisnaiah, K. (2002). Experimental investigation of the uplift behaviour of circular plate anchors embedded in sand. Can. Geotech. J., 39: 648-664.

18. Khatri, V. N., and Kumar, J. (2009). Vertical uplift resistance of circular plate anchors in clays under undrained condition. Computers and Geotechnics, 36(8):1352-1359.

19. Khatri, V. N., and Kumar, J. (2010). Stability of an unsupported vertical circular excavation in clays under undrained condition. Computers and Geotechnics, 37(3):419-424.

20. Khatri, V. N., and Kumar, J. (2011). Effect of anchor width on pullout capacity of strip anchors in sand. Canadian Geotechnical Journal, 48(3):511-517. 
21. Kouzer, K. M., and Kumar, J. (2009a). Vertical uplift capacity of two interfering horizontal anchors in sand using an upper bound limit analysis. Computers and Geotechnics, 36(6):1084-1089.

22. Kouzer, K. M., and Kumar, J. (2009b). Vertical uplift capacity of equally spaced horizontal strip anchors in sand. International Journal of Geomechanics, 9(5):230-236.

23. Kumar, J., and Kouzer, K.M. (2008a). Vertical uplift capacity of a group of shallow horizontal anchors in sand. Géotechnique, 58(10):821-823.

24. Kumar, J., and Naskar, T. (2012). Vertical uplift capacity of a group of two coaxial anchors in a general $c-\varphi$ soil. Canadian Geotechnical Journal, 49(3): 367-373.

25. Mabrouki, A., and Mellas, M. (2014). Étude tridimensionnelle de la capacité ultime des plaques d'ancrage dans un sol frottant. Courrier Du Savoir, (18):15-19.

26. Merifield, R.S., and Sloan, S.W. (2006). The ultimate pullout capacity of anchors in frictional soils. Can. Geotech. J. 43(8):852-868.

27. Merifield R S, Lyamin A V, Sloan S W (2006) Three dimensional lower bound solutions for the stability of plate anchors in sand. Géotechnique 56(2):123132.

28. Merifield, R.S and Smith, C.C. (2010). The ultimate uplift capacity of multiplate strip anchors in undrained clay. Computers and Geotechnics 37:504-514

29. Meyerhof, G. G. and Adams, J. I. (1968). The ultimate uplift capacity of foundations. Canadian Geotechnical Journal 5(4):225-244.

30. Meyerhof, G. G. (1973) "Uplift resistance of inclined anchors and piles" Proc. of VIII International Conference on Soil mechanics and Foundation Engineering, Moscow, USSR, 2, 1, 167-172. 
31. Mors, H. (1959). The behaviour of mast foundations subject to tensile forces. Bautechnik, 10: 367-378.

32. Murray, E. J., and Geddes, J. D. (1987). Uplift of anchor plates in sand. J. Geotech. Engrg., 113(3):202-215.

33. Rowe, R. K. and Davis, E. H. (1982b). The behaviour of anchor plates in sand. Géotechnique, 32(1):25-41.

550

34. Sahoo, J. P., and Kumar, J. (2014a). Vertical uplift resistance of two closely 551 spaced horizontal strip anchors embedded in cohesive - frictional weightless medium. Can. Geotech. J., 51:223-230.

35. Sahoo, J. P., and Kumar, J. (2014b). Vertical uplift resistance of two interfering horizontal anchors in clay. J. Geotech. Geoenviron. Eng., 140(4):06013007

555

36. Wang, D., Merifield, R.S., and Gaudin, C. (2013). Uplift behaviour of helical 556 anchors in clay. Can. Geotech. J. 50:575-584.

557

558

Appendix A: Analytical solution of break-out factor $\boldsymbol{N}_{\gamma \text { isolated }}$ for an isolated 559 square anchor plate

560 Volumes of the portions 1, 2 and 3 shown in Fig. 25:

$$
\begin{gathered}
V_{1}=B^{2} H \\
V_{2}=0.5 B H^{2} \tan \theta \\
V_{3}=\frac{1}{6} H^{3} \tan ^{2} \theta
\end{gathered}
$$

561 The ultimate pullout load $Q_{u}$ is equal to the weight of the soil located within the failure 562 mechanism:

$$
Q_{u}=\gamma\left(V_{1}+4 V_{2}+4 V_{3}\right)
$$

563 Using Equations 21, 22 and 23, we finally get: 


$$
Q_{u}=B^{2} \gamma H+2 \gamma H^{2} B \tan \theta+\frac{2}{3} \gamma H^{3} \tan ^{2} \theta
$$

564 By definition, the ultimate pullout capacity $q_{u}$ :

$$
\begin{gathered}
q_{u}=\frac{Q_{u}}{A}=\frac{Q_{u}}{B^{2}} \\
q_{u}=\gamma H\left(1+2 \frac{H}{B} \tan \theta+\frac{2}{3}\left(\frac{H}{B}\right)^{2} \tan ^{2} \theta\right)
\end{gathered}
$$

565 By convention, $q_{u}$ is also given by:

$$
q_{u}=\gamma H N_{\gamma}
$$

566 So that the break-out factor $N_{\gamma}$ for an isolated square plate anchor is:

$$
N_{\gamma \text { isolated }}=1+2 \frac{H}{B} \tan \theta+\frac{2}{3}\left(\frac{H}{B}\right)^{2} \tan ^{2} \theta
$$

567 Appendix B: Analytical solution of break-out factor $N_{\gamma \text { end }}$ for a square anchor

568 plate located at an end

569 For two or $\mathrm{n}$ square anchor plates with $S<2 H \tan \theta$, the ultimate pullout load of one 570 anchor plate at the end is equal to the weight of the soil located within its failure

571 mechanism defined by points a, b, c, d, e shown in Fig. 21.

572 Volumes of the portions 4 and 5 shown in Fig. 26:

$$
\begin{gathered}
V_{4}=\frac{1}{2}(2 H \tan \theta-S)\left(H-\frac{S}{2} \cot \theta\right) B \\
V_{4}=B H^{2} \tan \theta+B \frac{S^{2}}{4} \cot \theta-B S H \\
V_{5}=\frac{1}{3} \times \frac{1}{2}\left(\sqrt{2} H \tan \theta-S \frac{\sqrt{2}}{2}\right)^{2}\left(H-\frac{S}{2} \cot \theta\right) \\
V_{5}=\frac{1}{3} H^{3} \tan ^{2} \theta-\frac{1}{2} S H^{2} \tan \theta-\frac{S^{3}}{24} \cot \theta+\frac{1}{4} S^{2} H
\end{gathered}
$$

573 The volume $V$ corresponding to points $\mathrm{a}, \mathrm{b}, \mathrm{c}, \mathrm{d}$, e shown in Fig.16 is equal to:

$$
V=V_{T}-\frac{1}{2} V_{4}-2\left(\frac{1}{2} V_{5}\right)=V_{T}-\frac{V_{1}}{2}-V_{5}
$$


574 Where $V_{T}$ is the total volume of soil located within the failure mechanism for an

575 isolated square anchor plate.

576 So:

$$
\begin{gathered}
V=B^{2} H+\frac{3}{2} H^{2} B \tan \theta+\frac{1}{3} H^{3} \tan ^{2} \theta-\frac{1}{8} B S^{2} \cot \theta+\frac{1}{2} B S H+\frac{1}{2} S H^{2} \tan \theta \\
+\frac{1}{24} S^{3} \cot \theta-\frac{1}{4} S^{2} H
\end{gathered}
$$

577 The ultimate pullout capacity of anchor plate located at the end is then:

$$
q_{u \text { end }}=\frac{Q_{u \text { end }}}{A}=\frac{Q_{u \text { end }}}{B^{2}}=\frac{\gamma \times V}{B^{2}}
$$

578 Using Equation 35, we get:

$$
\begin{aligned}
q_{\text {u end }}=\gamma H(1 & +\frac{3}{2}\left(\frac{H}{B}\right) \tan \theta+\frac{1}{3}\left(\frac{H}{B}\right)^{2}(\tan \theta)^{2}-\frac{1}{8}\left(\frac{S}{B}\right)\left(\frac{S}{H}\right) \cot \theta+\frac{1}{2}\left(\frac{S}{B}\right) \\
+ & \left.\frac{1}{2}\left(\frac{S}{B}\right)\left(\frac{H}{B}\right) \tan \theta+\frac{1}{24}\left(\frac{S}{B}\right)^{2}\left(\frac{S}{H}\right) \cot \theta-\frac{1}{4}\left(\frac{S}{B}\right)^{2}\right)
\end{aligned}
$$

579 Since:

$$
q_{u \text { end }}=\gamma H N_{\gamma \text { end }}
$$

580 We finally obtained $N_{\gamma \text { end }}$

$$
N_{\gamma \text { end }}=1+\frac{1}{3}\left(\frac{H}{B}\right)^{2}(\tan \theta)^{2}+\frac{1}{2}\left(3+\frac{S}{B}\right) \frac{H}{B} \tan \theta+\frac{1}{8} \frac{S}{H} \frac{S}{B}\left(\frac{1}{3} \frac{S}{B}-1\right) \cot \theta-\frac{1}{4}\left(\frac{S}{B}\right)^{2}+\frac{1}{2} \frac{S}{B}
$$

581

Appendix C: Analytical solution of break-out factor $N_{\gamma \text { inter }}$ for an intermediate

583 square anchor plate

584 For $n$ square anchor plates in row configuration with $S<2 H \tan \theta$, the ultimate pullout 585 load of an intermediate anchor plate is equal to the weight of the soil located within 586 its failure mechanism defined by points $a, b, c, d, e, f$ as shown in Fig. 23. The break587 out factor corresponding to this volume is noted $N_{\gamma \text { inter }}$

588 The volume $V$ corresponds to points $\mathrm{a}, \mathrm{b}, \mathrm{c}, \mathrm{d}, \mathrm{e}, \mathrm{f}$ shown in Fig.18 is equal to: 


$$
V=V_{T}-2\left(\frac{1}{2} V_{4}\right)-4\left(\frac{1}{2} V_{5}\right)=V_{T}-V_{4}-2 V_{5}
$$

589 Where $V_{T}$ is the total volume of soil located within the failure mechanism for an

590 isolated square anchor plate.

591 Using Equations (31 and 33), we obtain:

$$
V=B^{2} H+H^{2} B \tan \theta-\frac{1}{4} B S^{2} \cot \theta+B S H-S H^{2} \tan \theta+\frac{1}{12} S^{3} \cot \theta-\frac{1}{2} S^{2} H
$$

592 The ultimate pullout capacity of one anchor plate located between two anchor plates

593 is given by:

$$
\begin{gathered}
q_{\text {u inter }}=\frac{Q_{u \text { inter }}}{A}=\frac{Q_{u \text { inter }}}{B^{2}}=\frac{\gamma \times V}{B^{2}} \\
q_{\text {u inter }}=\gamma H\left(1+\left(\frac{H}{B}\right) \tan \theta-\frac{1}{4}\left(\frac{S}{B}\right)\left(\frac{S}{H}\right) \cot \theta+\frac{S}{B}+\left(\frac{S}{B}\right)\left(\frac{H}{B}\right) \tan \theta\right. \\
\left.+\frac{1}{12}\left(\frac{S}{B}\right)^{2}\left(\frac{S}{H}\right) \cot \theta-\frac{1}{2}\left(\frac{S}{B}\right)^{2}\right)
\end{gathered}
$$

594 Since:

$$
q_{u \text { inter }}=\gamma H N_{\gamma \text { inter }}
$$

595 We get:

$$
N_{\gamma \text { inter }}=1+\left(1+\frac{S}{B}\right) \frac{H}{B} \tan \theta-\frac{1}{3} \frac{S}{B} \frac{S}{H}\left(\frac{1}{4} \frac{S}{B}-1\right) \cot \theta-\frac{1}{2}\left(\frac{S}{B}\right)^{2}+\frac{S}{B}
$$

596

597 List of figures captions:

598 Fig. 1 Geometrical model of group of four square anchor plates

599 Fig. 2 Total displacements for an isolated square anchor plate $(H / B=4)$

600 Fig. 3 Influence of Young's modulus on the pullout load for an isolated plate $(H / B=4$,

$$
H / B=6)
$$

602 Fig. 4 Group of square anchor plates in row configuration

603 Fig. 5 The ultimate pullout load versus displacement for two anchor plates with varying spacing and an isolated anchor plate 
605 Fig. 6 Deformed mesh for two anchor plates, $H / B=2$ and $S / B=2$

606 Fig. 7 Group efficiency of square anchor plates in row configuration

607 Fig. 8 Group of square anchor plates in square configuration

608 Fig. 9 Total displacements for nine $(3 \times 3)$ anchor plates in square configuration, $H / B$ $=4$ and $S / B=2$

610 Fig. 10 Group efficiency for four and nine plates in square configuration

611 Fig. 11 Load factor of group of square plates in row configuration

612 Fig. 12 Load factor of group of square plates in square configuration

613 Fig. 13 Influence of installation depth on the group efficiency

614 Fig. 14 Total displacements for a group of two plates with $H / B=4 ; 6 ; 8$ and 10

615 Fig. 15 Influence of internal friction angle of soil on the group efficiency

616 Fig. 16 Influence of dilation angle on the group efficiency

617 Fig. 17 Influence of anchor roughness on the group efficiency

618 Fig. 18 Modified failure mechanism

619 Fig. 19 Break-out factor for square anchor plate in cohesionless soil

620 Fig. 20 Comparison of analytical and numerical Break-out factor for square anchor plate $(B=1 \mathrm{~m})$ in cohesionless soil

622 Fig. 21 Interference of two anchor plates: (a) 3D view, (b) Cross section A-A'

623 Fig. 22 Numerical, analytical and experimental comparison of group efficiency of two square anchor plates

625 Fig. 23 Interference of $n$ square anchor plates: (a) 3D view, (b) Cross section A-A'

626 Fig. 24 Comparison of numerical, analytical and experimental results of group 627 efficiency of five square plates in row configuration

628 Fig. 25 Failure mechanism for isolated square plate

629 Fig. 26 Interference detail of two failure mechanisms 


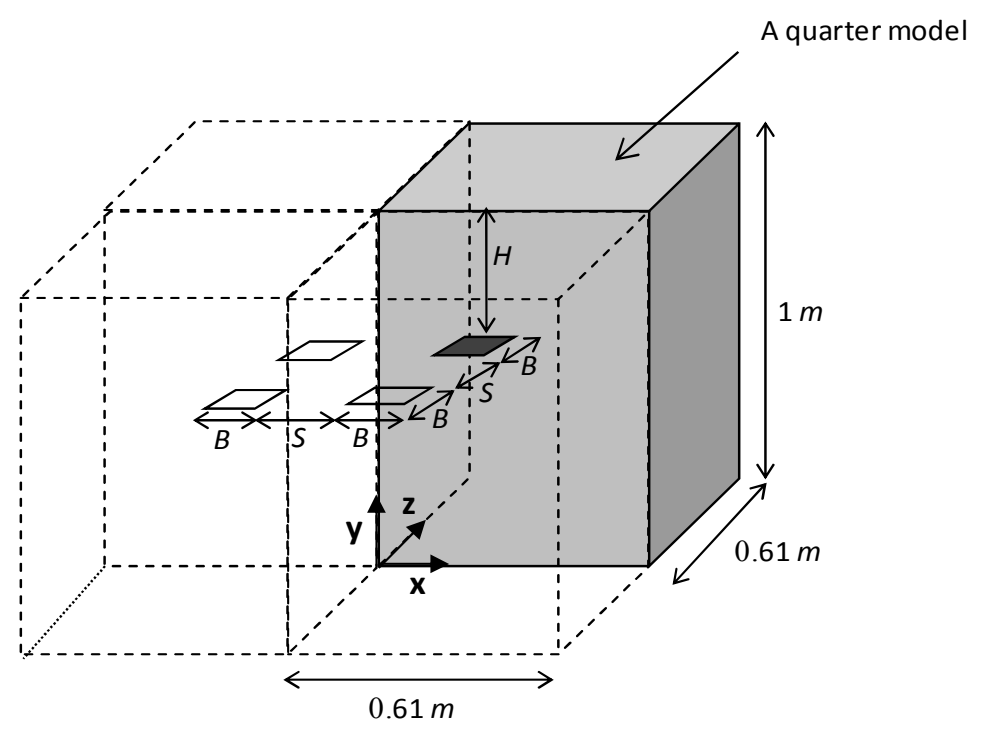

Fig. 1 


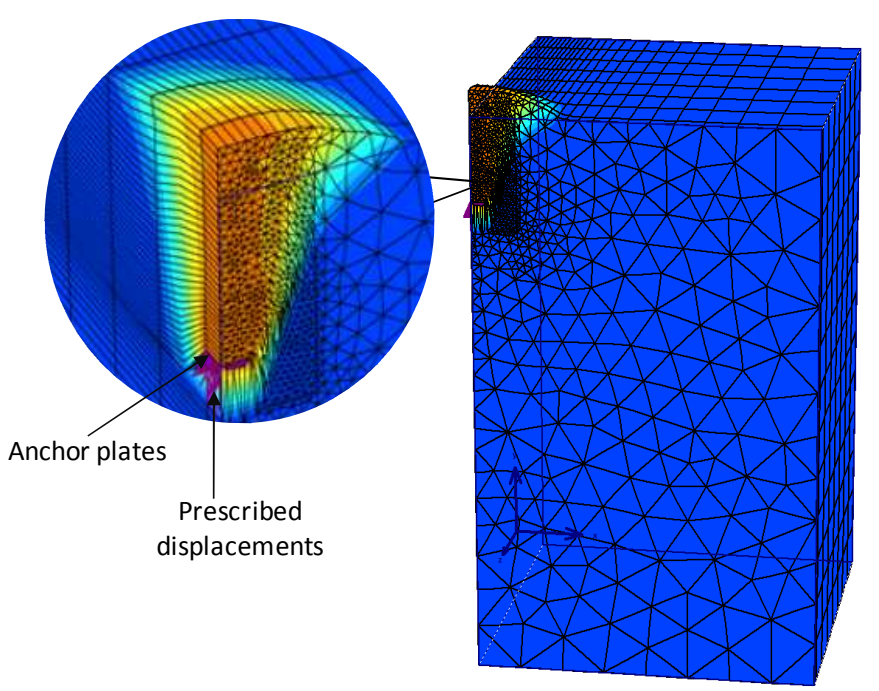

Fig. 2 


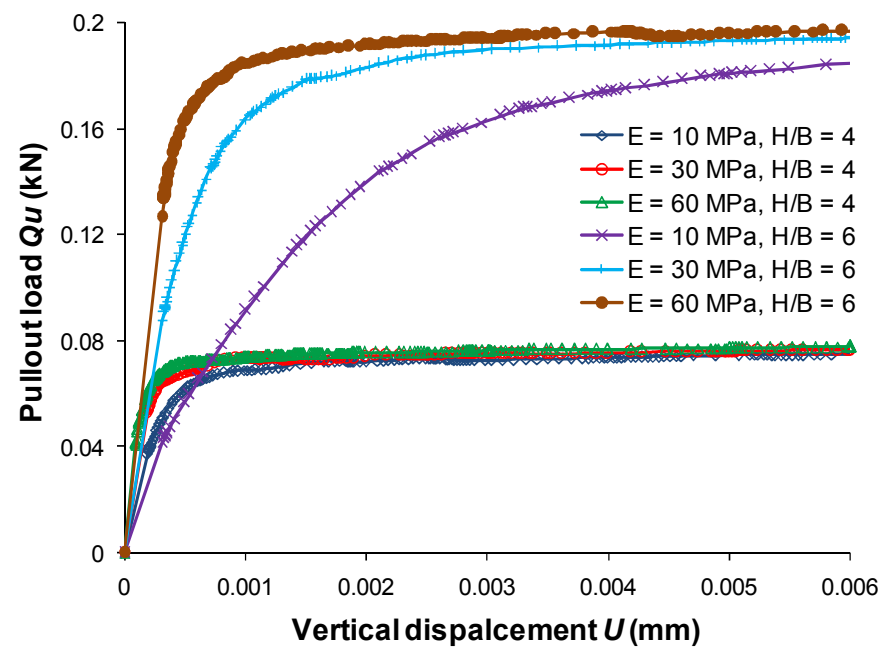

Fig. 3 


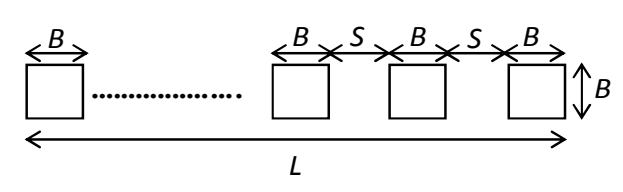

Fig. 4 


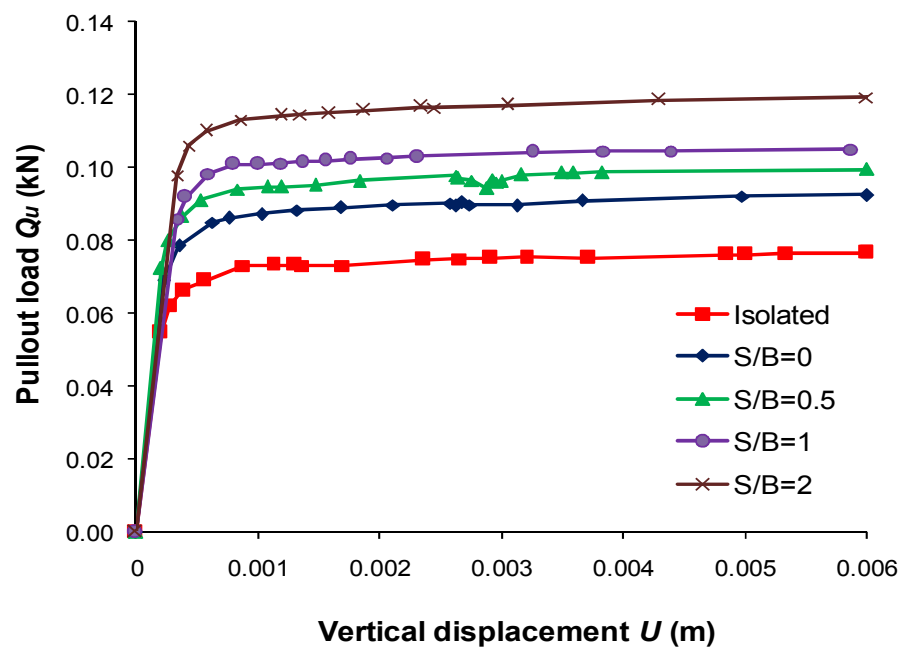

Fig. 5 


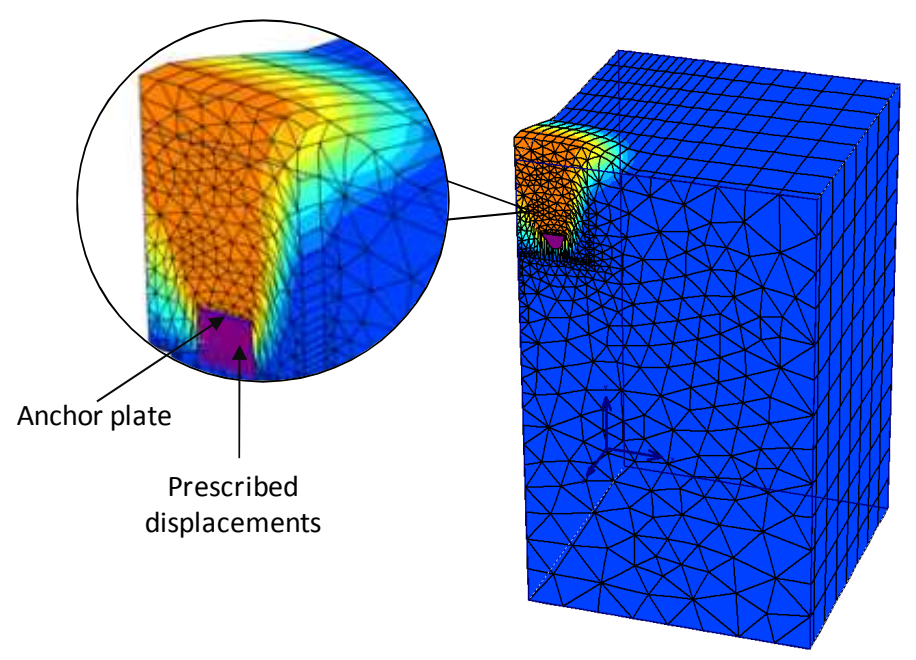

Fig. 6 


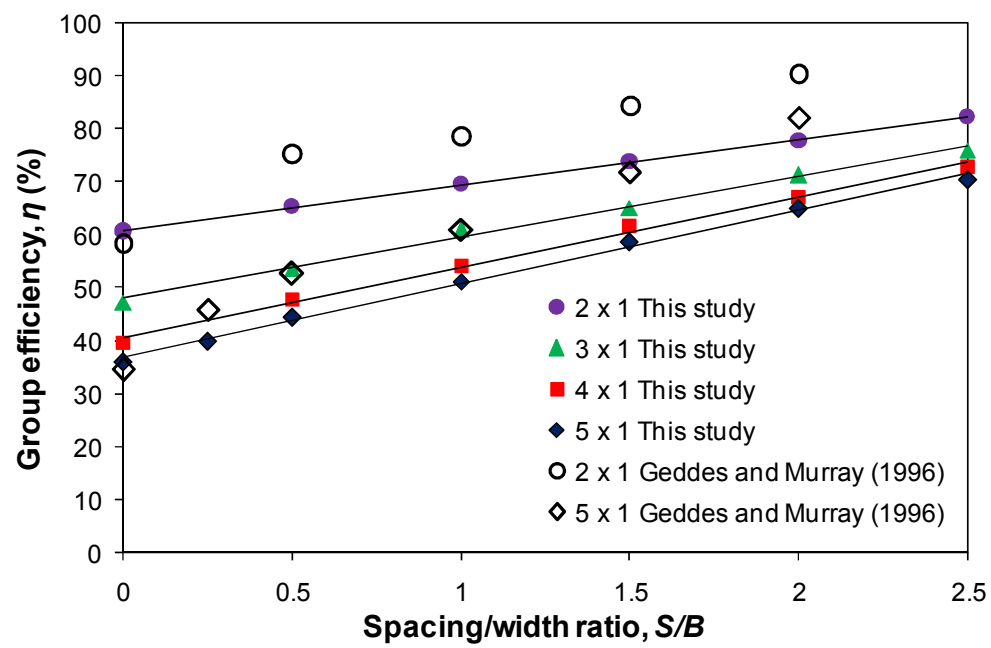

Fig. 7 


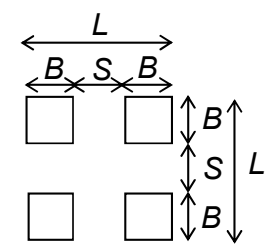

(a) Four (2x2) plates

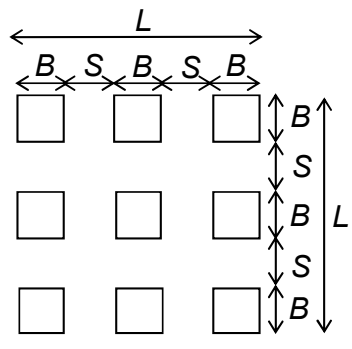

(b) Nine $(3 \times 3)$ plates

Fig. 8 


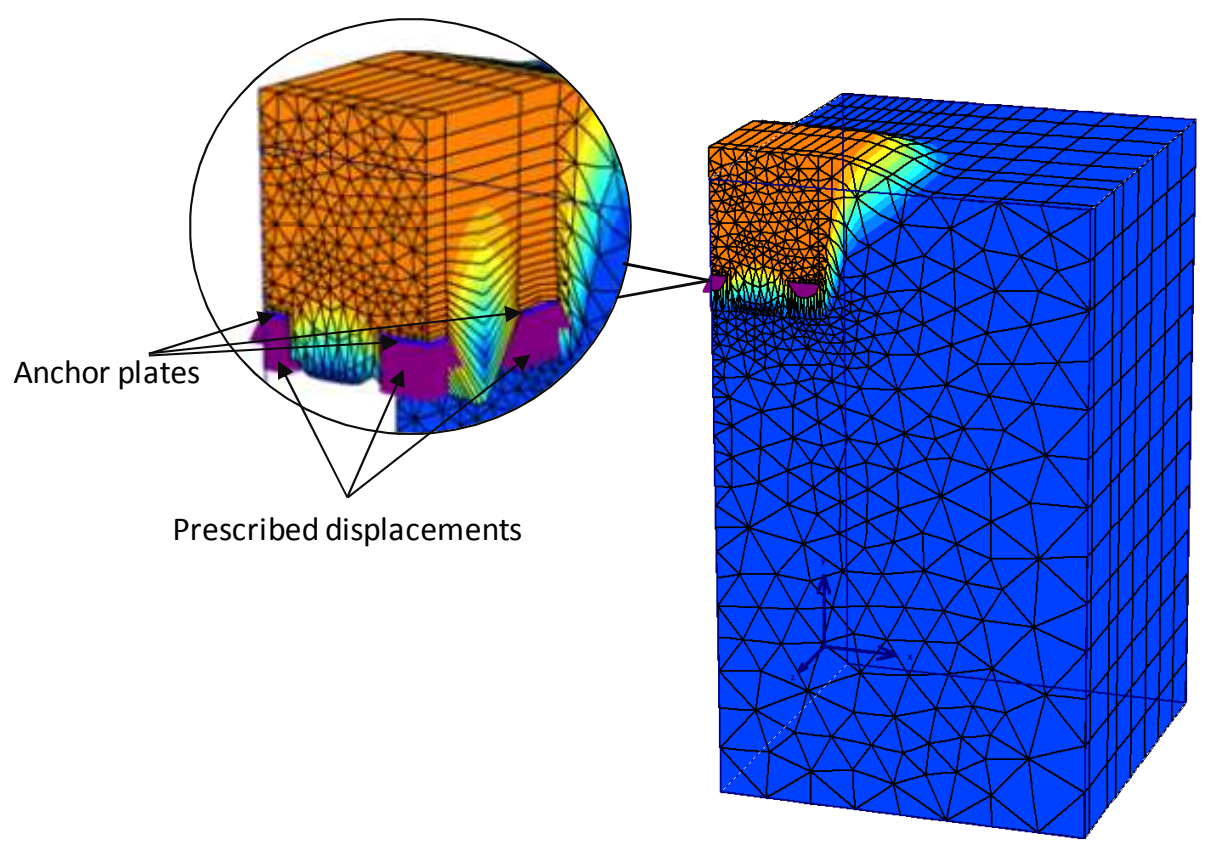

Fig. 9 


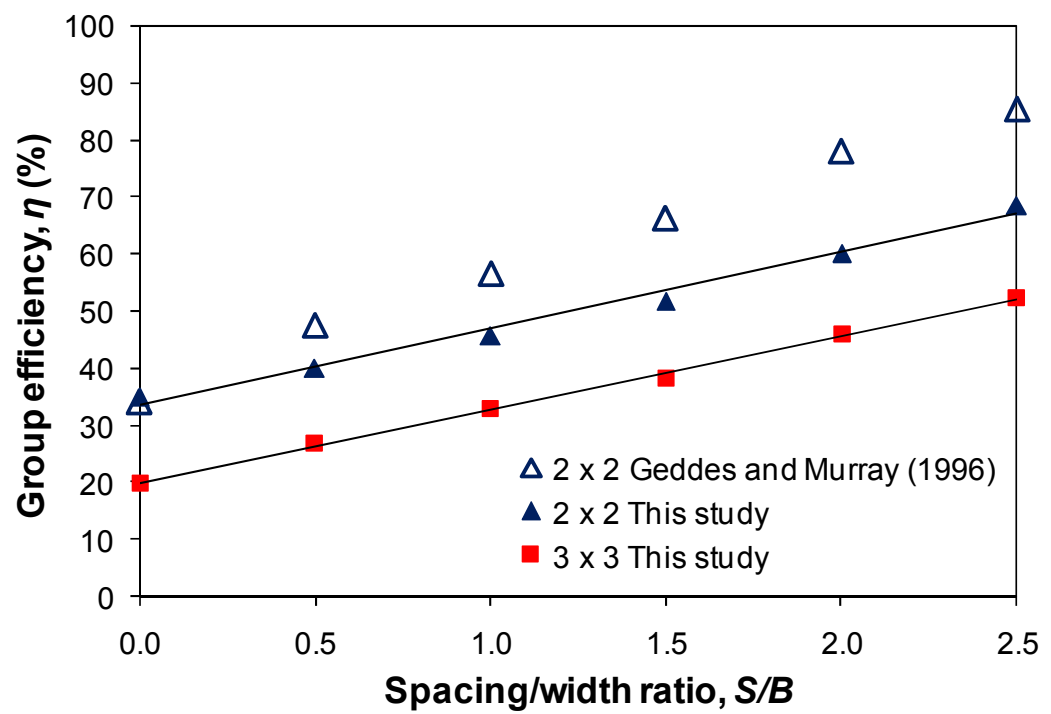

Fig. 10 


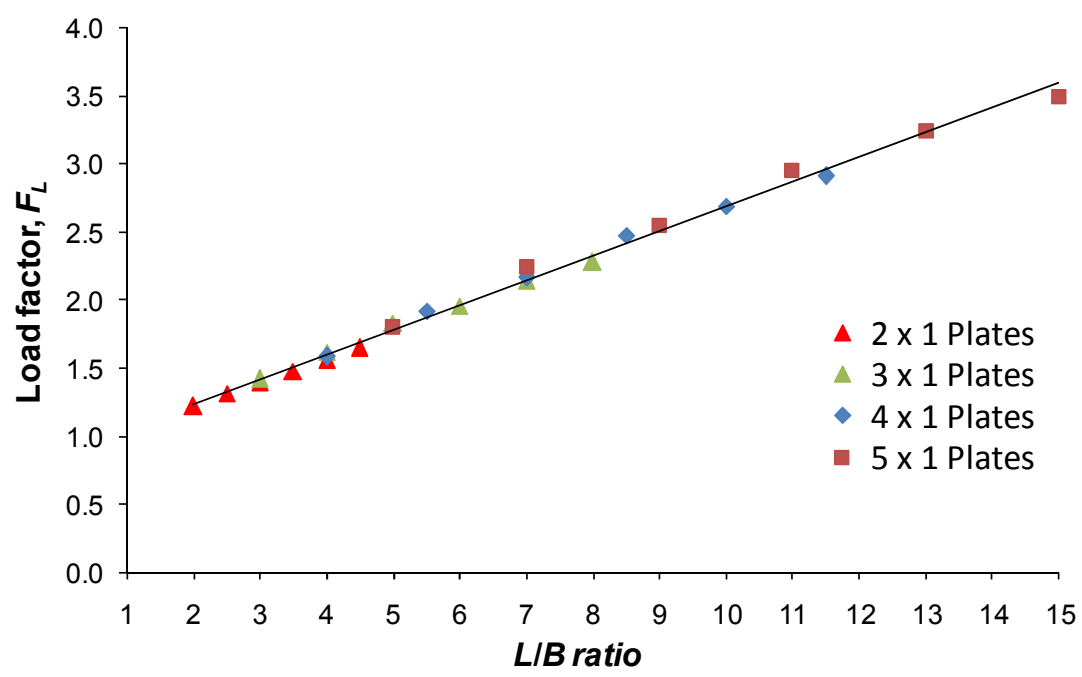

Fig. 11 


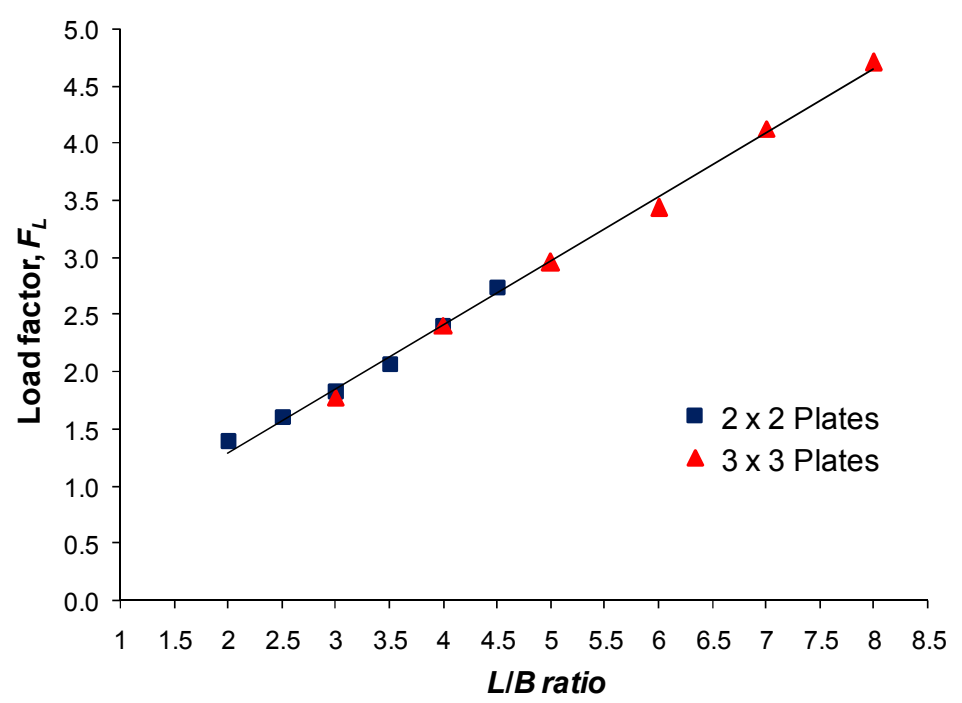

Fig. 12 


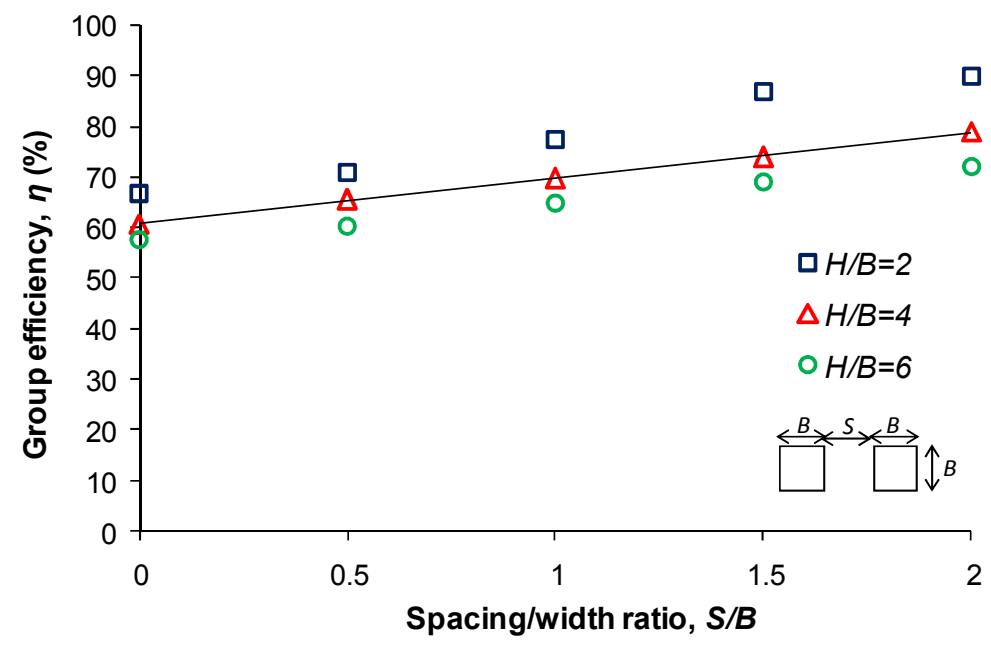

Fig. 13 

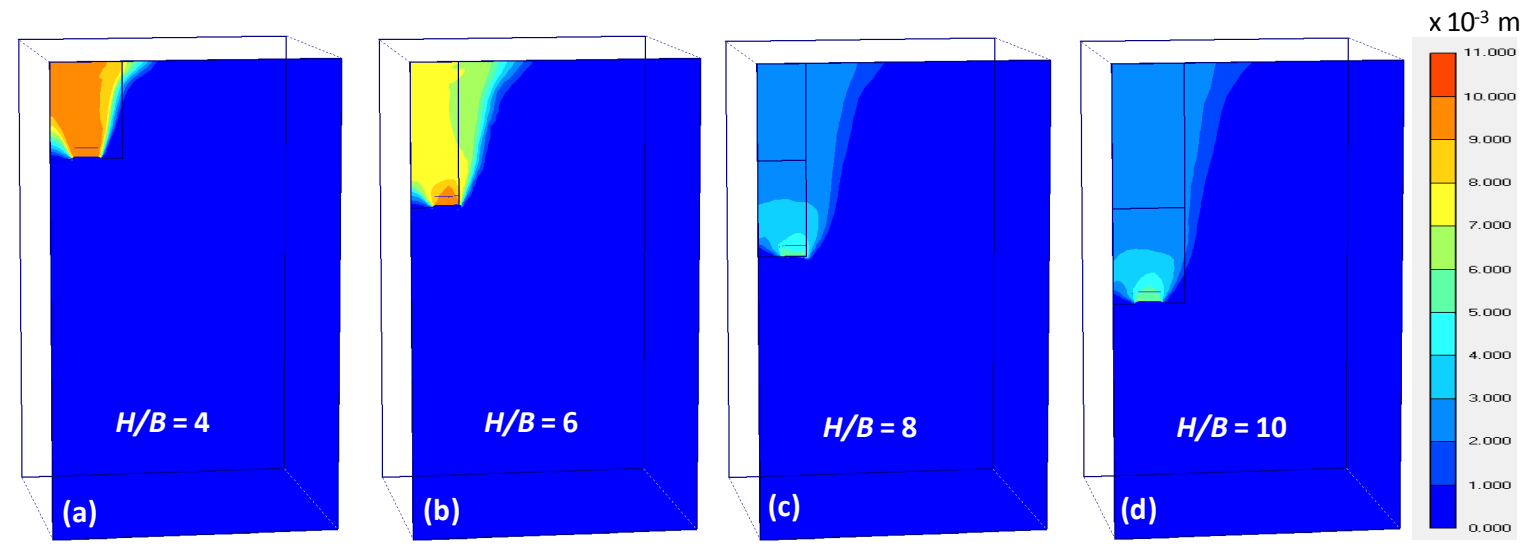

Fig. 14 


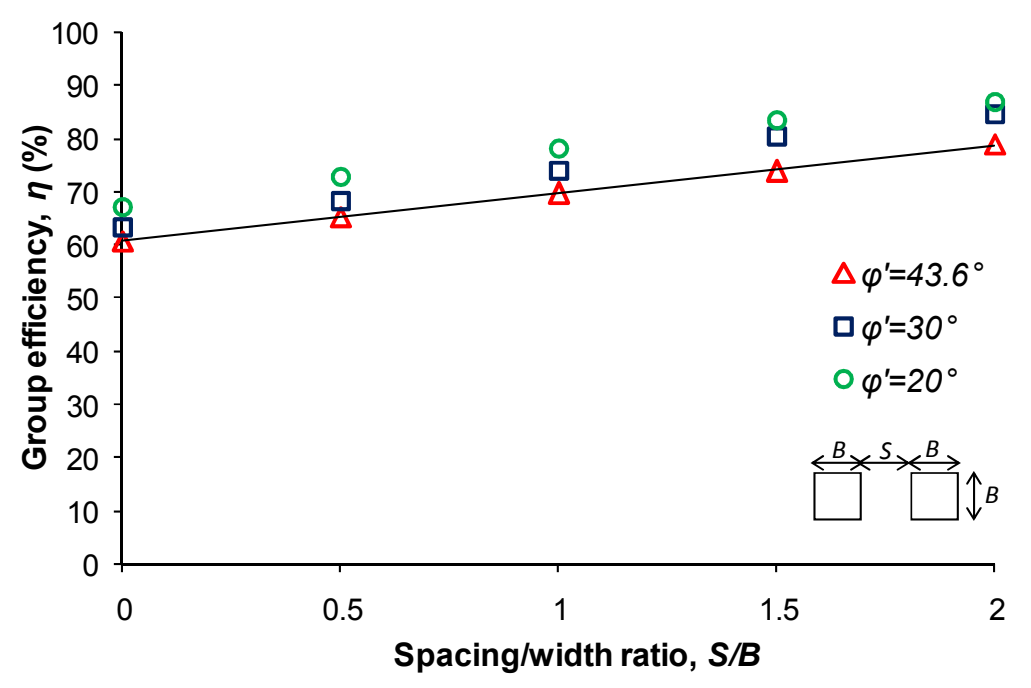

Fig. 15 


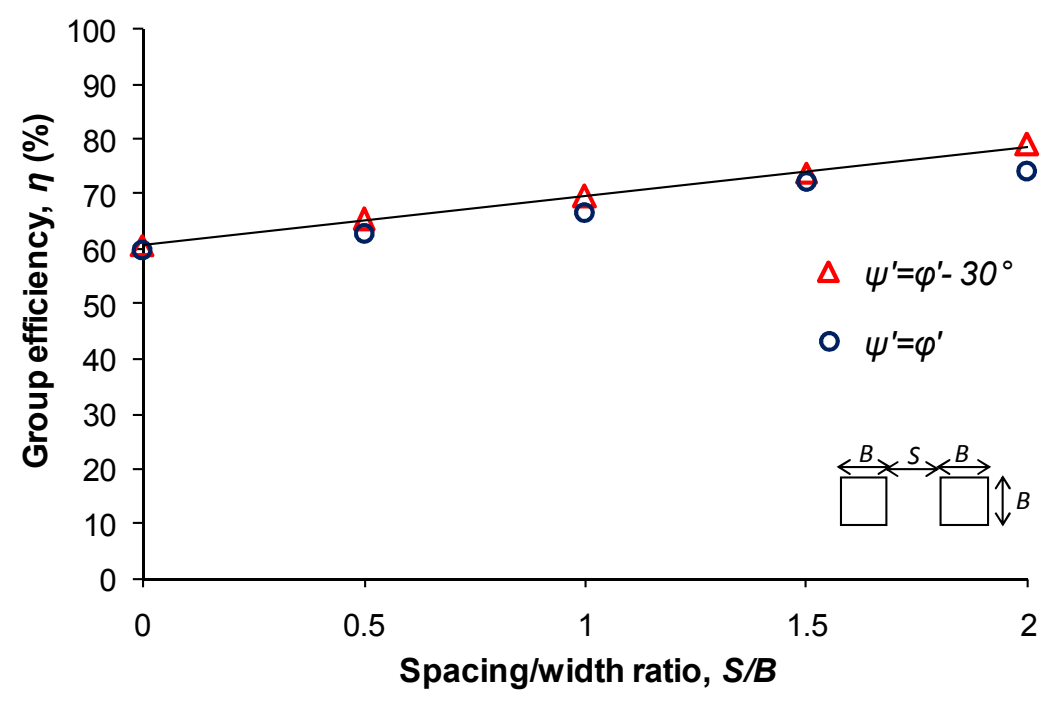

Fig. 16 


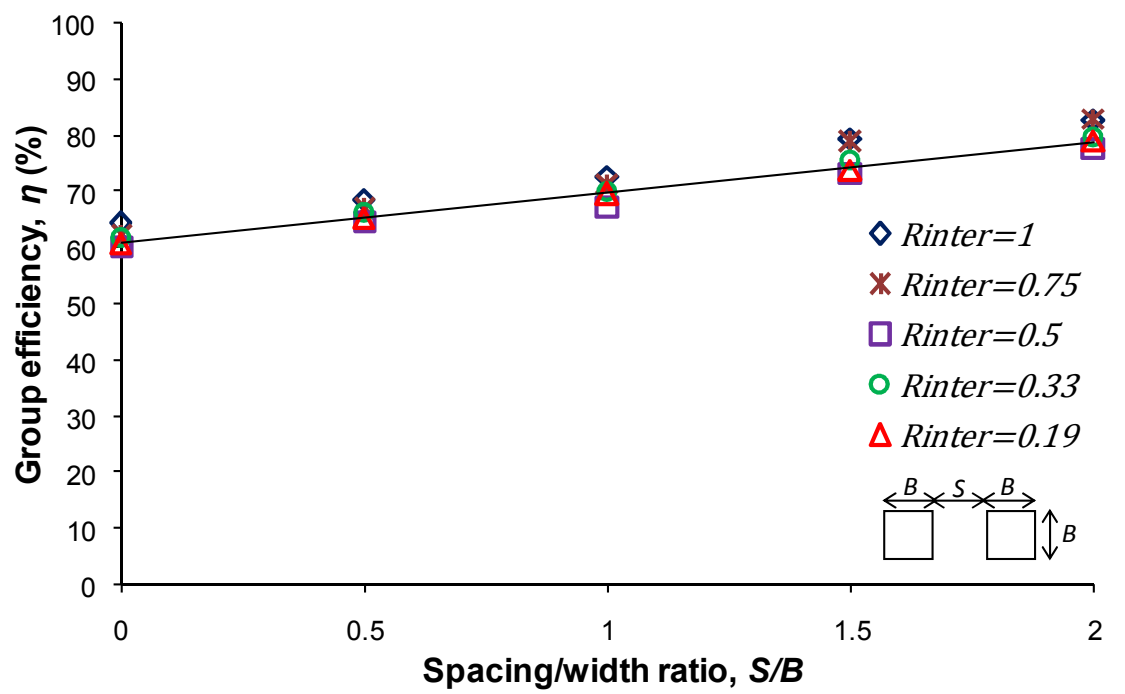

Fig. 17 


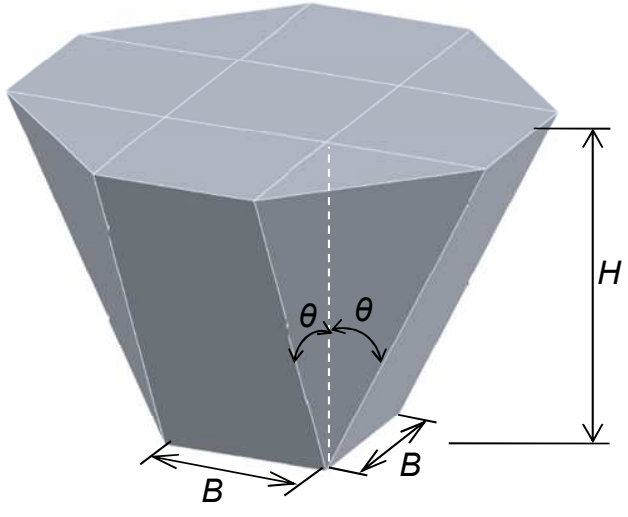

Fig. 18 


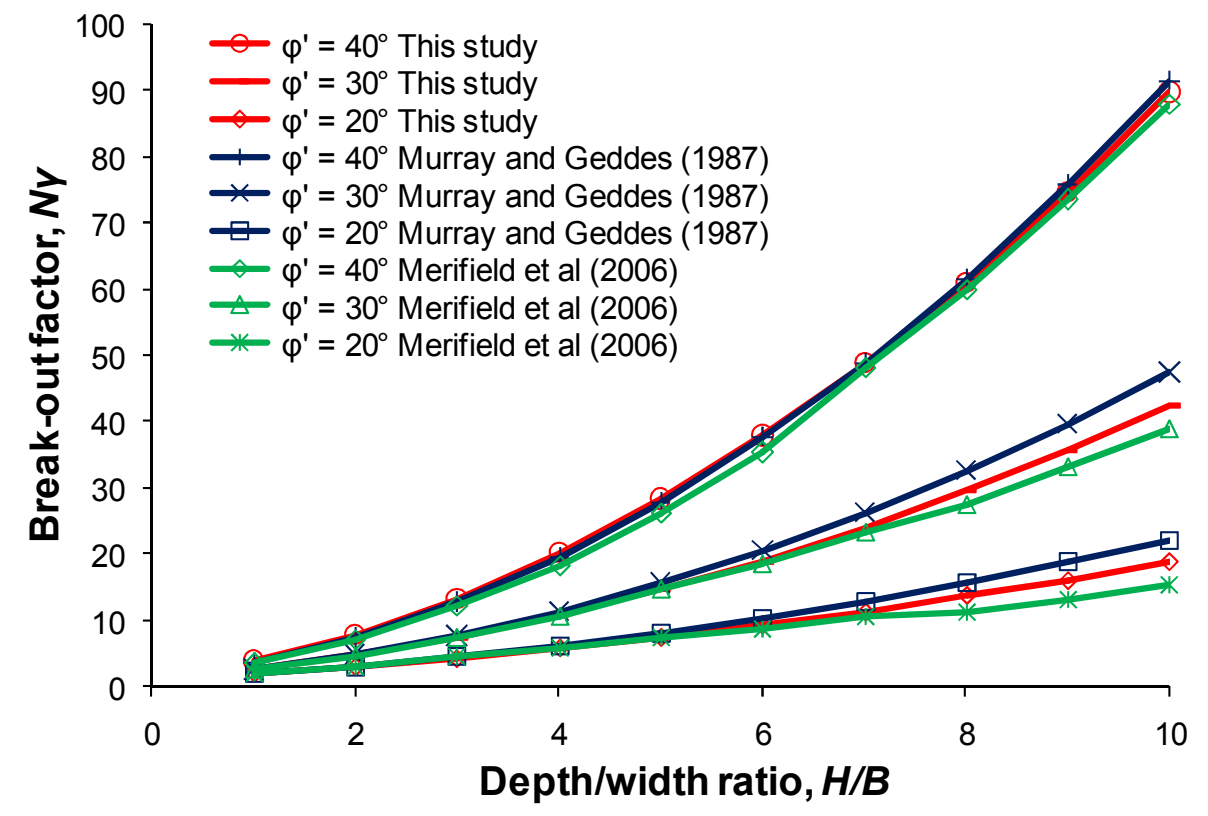

Fig. 19 


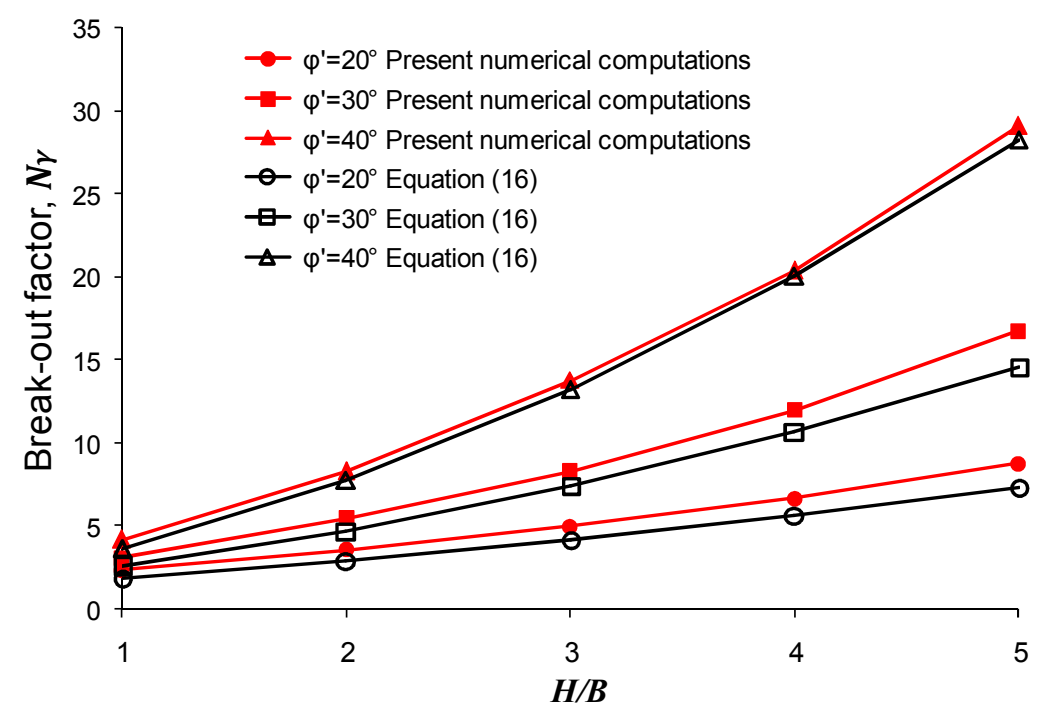

Fig. 20 


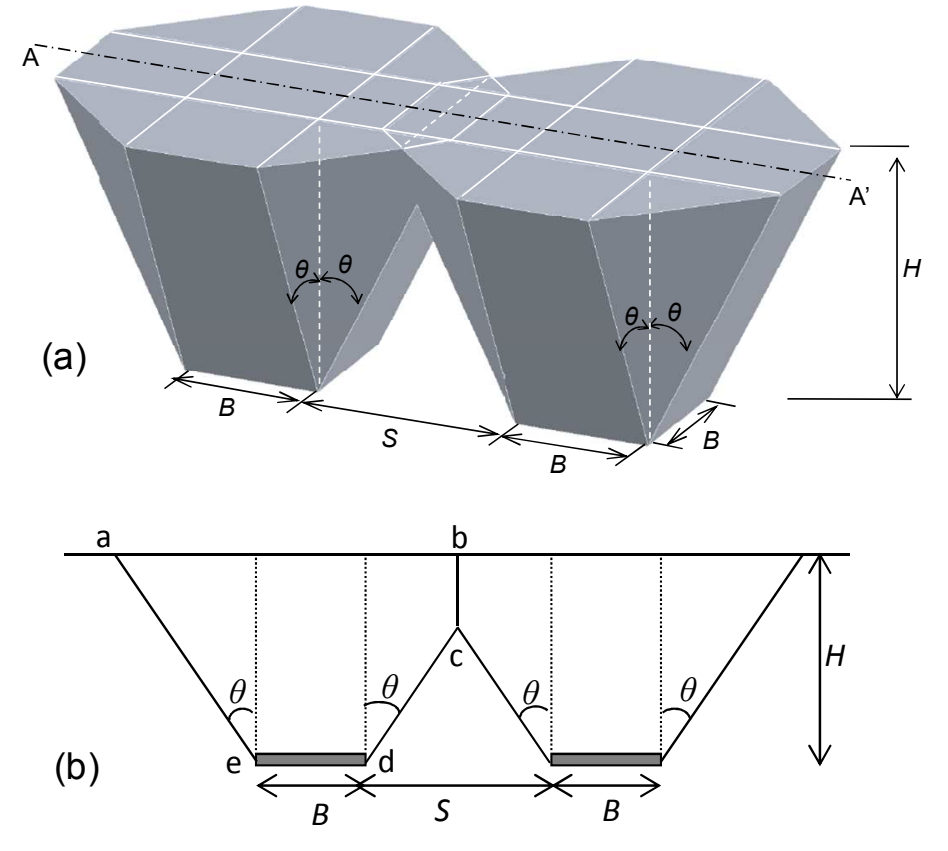

Fig. 21 


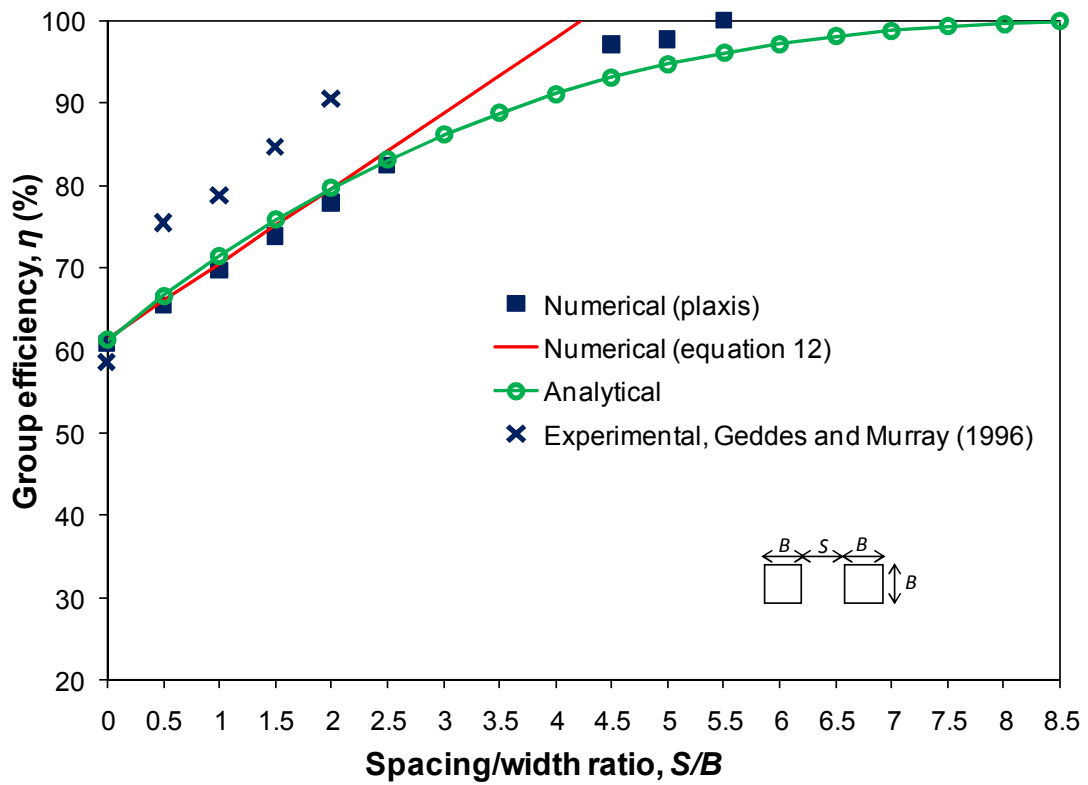

Fig. 22 

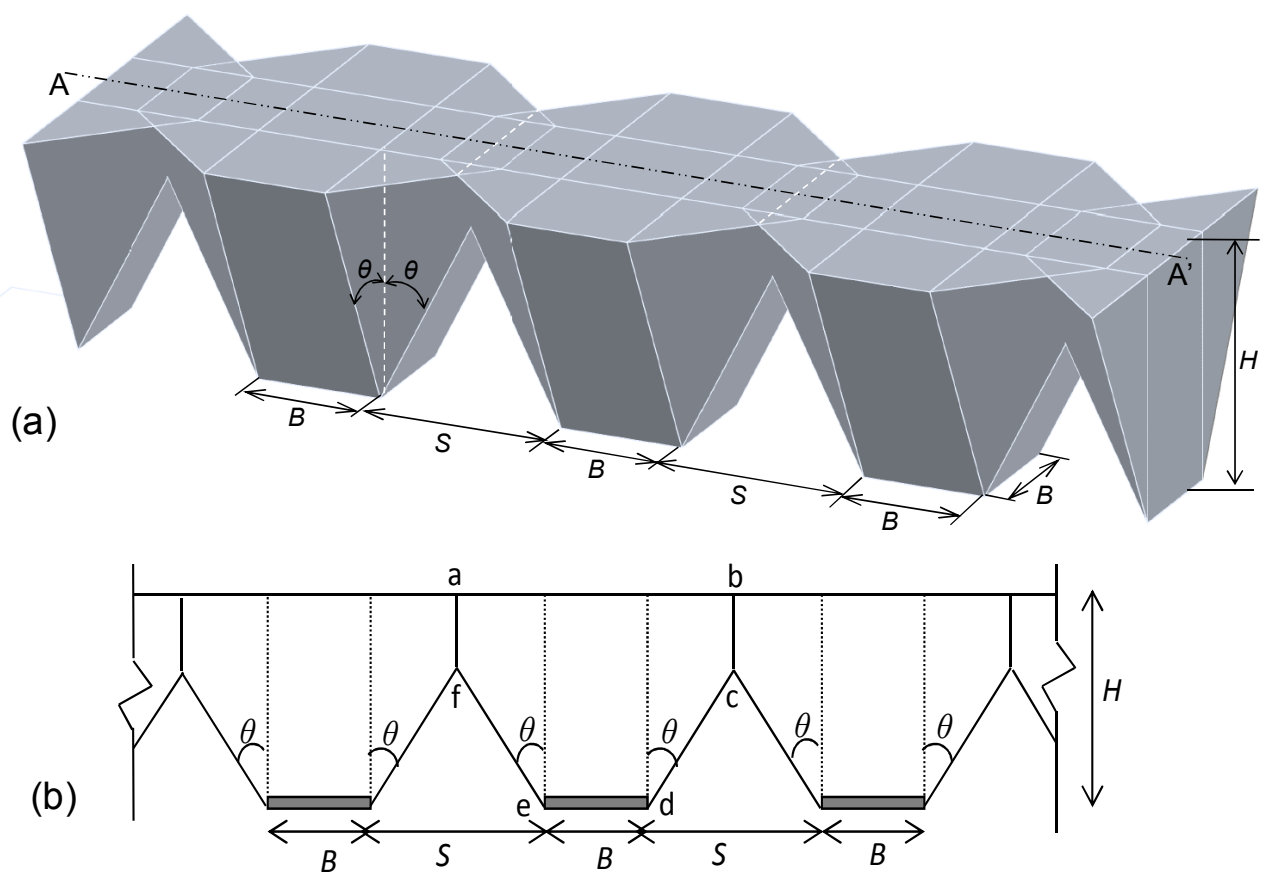

Fig. 23 


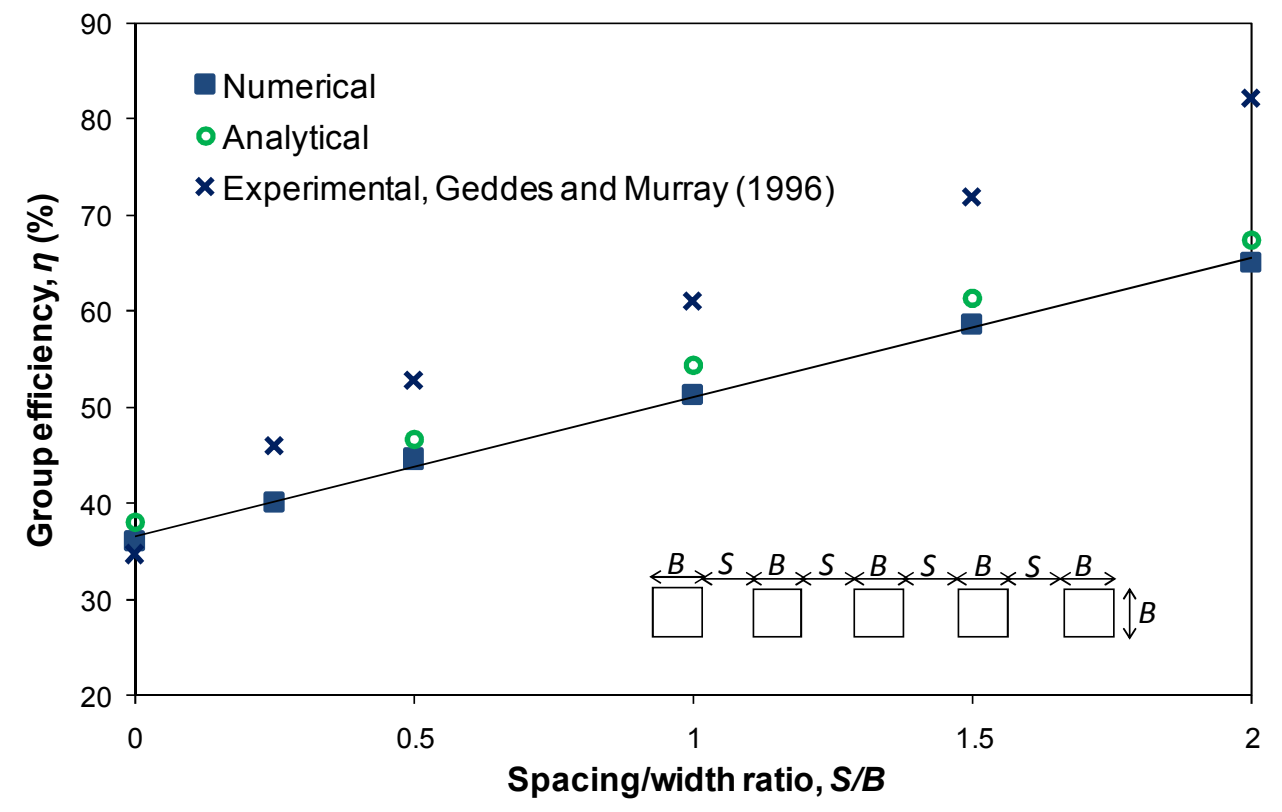

Fig. 24 


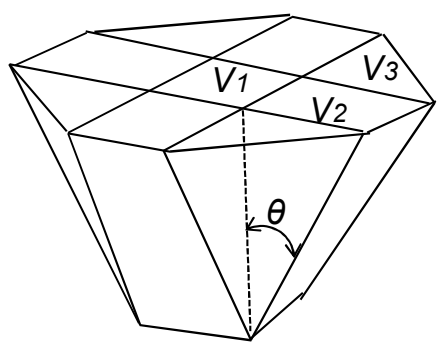

Fig. 25 


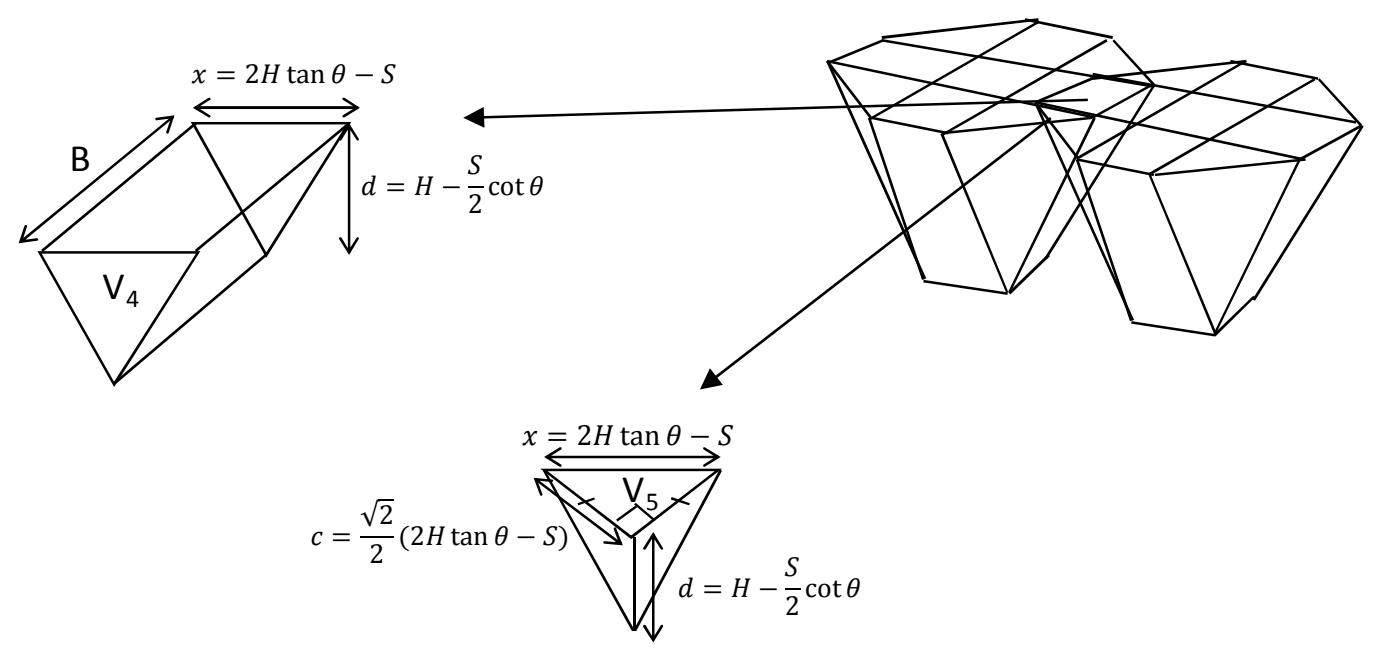

Fig. 26 